\title{
Intermolecular dissociation energies of 1-naphthol-n-alkane complexes
}

Richard Knochenmuss, Surajit Maity, Franziska Balmer, Charlotte Müller, and Samuel Leutwyler

Citation: The Journal of Chemical Physics 149, 034306 (2018); doi: 10.1063/1.5034110

View online: https://doi.org/10.1063/1.5034110

View Table of Contents: http://aip.scitation.org/toc/jcp/149/3

Published by the American Institute of Physics

ADVANCED LIGHT CURE ADHESIVES

\section{PHYSICS TODAY}

WHITEPAPERS
Take a closer look at what these environmentally friendly adhesive systems can do
READ NOW

PRESENTED BY

Q MASTERBOND' 


\title{
Intermolecular dissociation energies of 1-naphthol-n-alkane complexes
}

\author{
Richard Knochenmuss, Surajit Maity, ${ }^{a}$ Franziska Balmer, Charlotte Müller, \\ and Samuel Leutwyler b) \\ Department of Chemistry and Biochemistry, University of Bern, Freiestrasse 3, \\ CH-3012 Bern, Switzerland
}

(Received 9 April 2018; accepted 26 June 2018; published online 17 July 2018)

\begin{abstract}
Using the stimulated-emission-pumping/resonant 2-photon ionization (SEP-R2PI) method, we have determined accurate intermolecular dissociation energies $D_{0}$ of supersonic jet-cooled intermolecular complexes of 1-naphthol $(1 \mathrm{NpOH})$ with alkanes, $1 \mathrm{NpOH} \cdot \mathrm{S}$, with $\mathrm{S}=$ methane, ethane, propane, and $n$-butane. Experimentally, the smaller alkanes form a single minimum-energy structure, while 1-naphthol- $n$-butane forms three different isomers. The ground-state dissociation energies $D_{0}\left(S_{0}\right)$ for the complexes with propane and $n$-butane (isomers $\mathrm{A}$ and $\mathrm{B}$ ) were bracketed within $\pm 0.5 \%$, being $16.71 \pm 0.08 \mathrm{~kJ} / \mathrm{mol}$ for $\mathrm{S}=$ propane and $20.5 \pm 0.1 \mathrm{~kJ} / \mathrm{mol}$ for isomer $\mathrm{A}$ and $20.2 \pm 0.1 \mathrm{~kJ} / \mathrm{mol}$ for isomer B of $n$-butane. All $1 \mathrm{NpOH} \cdot \mathrm{S}$ complexes measured previously exhibit a clear dissociation threshold in their hot-band detected SEP-R2PI spectra, but weak SEP-R2PI bands are observed above the putative dissociation onset for the methane and ethane complexes. We attribute these bands to long-lived complexes that retain energy in rotation-type intermolecular vibrations, which couple only weakly to the dissociation coordinates. Accounting for this, we find dissociation energies of $D_{0}\left(S_{0}\right)=7.98 \pm 0.55 \mathrm{~kJ} / \mathrm{mol}( \pm 7 \%)$ for $\mathrm{S}=$ methane and $14.5 \pm 0.28 \mathrm{~kJ} / \mathrm{mol}( \pm 2 \%)$ for $\mathrm{S}=$ ethane. The $D_{0}$ values increase by only $1 \%$ upon $S_{0} \rightarrow S_{1}$ excitation of 1-naphthol. The dispersion-corrected density functional theory methods B97-D3, B3LYP-D3, and $\omega \mathrm{B} 97 \mathrm{X}-\mathrm{D}$ predict that the $n$-alkanes bind dispersively to the naphthalene "Face." The assignment of the complexes to Face structures is supported by the small spectral shifts of the $S_{0} \rightarrow S_{1}$ electronic origins, which range from +0.5 to $-15 \mathrm{~cm}^{-1}$. Agreement with the calculated dissociation energies $D_{0}\left(S_{0}\right)$ is quite uneven, the B97-D3 values agree within 5\% for propane and $n$-butane, but differ by up to $20 \%$ for methane and ethane. The $\omega$ B $97 X-D$ method shows good agreement for methane and ethane but overestimates the $D_{0}\left(S_{0}\right)$ values for the larger $n$-alkanes by up to $20 \%$. The agreement of the B3LYP-D3 $D_{0}$ values is intermediate between the other two methods. (C) 2018 Author(s). All article content, except where otherwise noted, is licensed under a Creative Commons Attribution (CC BY) license (http://creativecommons.org/licenses/by/4.0/). https://doi.org/10.1063/1.5034110
\end{abstract}

\section{INTRODUCTION}

London dispersion forces arise from long-range electron correlation between atoms and molecules. ${ }^{1,2}$ These noncovalent interactions between atoms or molecules are always attractive and are present in all forms of condensed matter. They contribute importantly to the structures and lattice energies of molecular solids and are involved in phenomena such as enzyme-substrate binding, drug-substrate interactions, and protein folding, so they are of great importance in fields ranging from solid-state physics to chemical biology. ${ }^{3-13}$ Although London dispersion energies between two closed-shell atoms are fairly weak, ${ }^{1-7}$ they increase with the number of atoms in molecular systems, so their additive nature is easily underestimated. When many atoms are in close

\footnotetext{
a)Present address: Department of Chemistry, Indian Institute of Technology Hyderabad, Kandi, Sangareddy 502285, India.

b)samuel.leutwyler@dcb.unibe.ch
}

proximity, as in molecular complexes, the dispersive contributions to the intermolecular binding energy may be larger than those from electrostatics, even when polar species are considered. When predominantly nonpolar species interact, London dispersion is usually the dominant binding energy contribution.

Calculations of dispersive interactions between polyatomic molecules are still remarkably challenging for wave function methods, since high-level correlated methods and large diffuse basis sets are necessary to accurately capture the intermolecular correlation energy. ${ }^{13-20}$ In density-functional theory (DFT), the introduction of dispersion-corrected functionals has provided a major advance. ${ }^{21-25}$ However, the parametrization of the dispersion terms employed in DFT-D methods has mainly been based on calculations, ${ }^{9,22,23,26,27}$ and the databases used to benchmark DFT-D calculations of dispersively bound complexes are themselves mostly based on calculations. ${ }^{14,16,17}$ Of the noncovalent interaction energies in the GMTKN30 database, ${ }^{9,28}$ only six dissociation energies are based on experiment. ${ }^{29,30}$ It is therefore important to gather 
accurate experimental benchmark data for benchmarking high-level correlated quantum chemical methods, dispersioncorrected DFT methods, for the parametrization of force-field models used in fields ranging from crystallography to biochemistry and to improve our understanding of intermolecular bonding. ${ }^{13,15,18-20,25}$

Using the stimulated-emission pumping resonant twophoton ionization (SEP-R2PI) method, ${ }^{13,31-37}$ we have recently determined accurate ground state $\left(S_{0}\right)$ intermolecular dissociation energies $D_{0}\left(S_{0}\right)$ of the intermolecular 1-naphthol. $\mathrm{S}$ complexes with noble gas atoms $(\mathrm{S}=\mathrm{Ne}$, $\mathrm{Ar}, \mathrm{Kr}, \mathrm{Xe}$ ) and with $\mathrm{N}_{2}$ which lie in the range between $D_{0}=3.4$ and $10.8 \mathrm{~kJ} / \mathrm{mol}^{37}$ These complexes are dispersively bound, with $\mathrm{S}$ on a Face of the naphthalene moiety. Increasing the size of the solvent $\mathrm{S}$ to nonpolar cycloalkanes leads to considerable increases of the dissociation energies, which range from $D_{0}=17.0 \mathrm{~kJ} / \mathrm{mol}$ for $\mathrm{S}=$ cyclopropane to $22.1 \mathrm{~kJ} / \mathrm{mol}$ for $\mathrm{S}=$ cycloheptane. ${ }^{35,36,38}$ In this work, we bridge the gap between the atomic and small-molecule $\left(\mathrm{N}_{2}\right)$ solvents and the cycloalkane solvents by measuring the dissociation energies of $1 \mathrm{NpOH} \cdot$ alkane complexes ranging from $\mathrm{S}=$ methane to $\mathrm{S}=n$-butane. Thus, the experimental $D_{0}\left(S_{0}\right)$ energies of these fifteen dispersively bound 1-naphthol complexes with nonpolar solvents from $\mathrm{Ne}$ to cycloheptane now cover a near-contiguous range between 3 and $22 \mathrm{~kJ} / \mathrm{mol}$. This allows us to test correlations of $D_{0}\left(S_{0}\right)$ with properties of the isolated solvent atoms or molecules.

The SEP-R2PI measurements for $1 \mathrm{NpOH} \cdot$ methane and $1 \mathrm{NpOH} \cdot$ ethane revealed more gradual dissociation energy thresholds than observed for all other $1 \mathrm{NpOH} \cdot \mathrm{S}$ complexes to date. This phenomenon is interpreted in terms of the very weak coupling of the three (two) internal-rotational-type intermolecular vibrations of methane (ethane) to the translation-type dissociation coordinates.

We also compare the experimental dissociation energies $D_{0}\left(S_{0}\right)$ to those calculated by three dispersion-corrected DFT methods. The calculated intermolecular binding energies $D_{e}$ of the minimum-energy structures are corrected for the zero-point vibrational energy (ZPVE) contributions both from the intermolecular ZPVE of the six new vibrations that arise between the 1-naphthol and $n$-alkane moieties and for the change of the intramolecular ZPVE of the two monomer moieties that arise upon complex formation. We discuss all three contributions to $D_{0}\left(S_{0}\right)$. Calculations of these complexes by highly correlated $a b$ initio methods would be very desirable, ${ }^{13,18,19,35}$ but are outside the scope of this work.

Fujii et al. have previously measured the $D_{0}\left(S_{0}\right)$ values of complexes of benzene (Bz) with $\mathrm{S}=$ methane $^{39}$ and $\mathrm{S}=$ ethane, propane, $n$-butane, iso-butane, and cyclohexane. ${ }^{40}$ Their $D_{0}\left(S_{0}\right)$ determinations of the neutral complexes involved measuring the $D_{0}$ of the respective $\mathrm{Bz}^{+} \cdot \mathrm{S}$ cation ground states, combined with measurements of the ionization potentials (IPs) of bare benzene and of $\mathrm{Bz} \cdot \mathrm{S}$, using the two-color R2PI technique. They compared their experimental values to coupled-cluster single, double and perturbative triple excitations $[\operatorname{CCSD}(\mathrm{T})]$ calculated dissociation energies, which agree well with the measured values. ${ }^{39,40}$ We compare the two sets of experimental $D_{0}$ measurements of alkane complexes in Sec. IV.

\section{METHODS}

\section{A. Experimental}

The $1 \mathrm{NpOH} \cdot n$-alkane complexes were formed and cooled in supersonic expansions of $0.2 \%-0.3 \%$ of the $n$-alkane diluted into Ne gas (99.99\% purity). The gas mixture at a stagnation pressure of 1.5 bar was passed over the 1-naphthol (1-NpOH) that was heated to $353 \mathrm{~K}$ ( 0.5 mbar vapor pressure) in the pulsed valve (nozzle diameter $0.4 \mathrm{~mm}$ ). The resulting supersonic jet was skimmed and then passed into the source region of a $1.2 \mathrm{~m}$ linear time-of-flight mass spectrometer.

The $S_{0}$ state dissociation energies of the jet-cooled 1-naphthol-S complexes are determined using vibrational predissociation (VP) in the $S_{0}$ state. High vibrational levels of the ground state complex are populated using stimulated-emission pumping (SEP) $)^{41}$ via the $S_{0} \leftrightarrow S_{1}$ transition. ${ }^{13,31-36,38,42}$ Following the "pump" and "dump" steps, the vibrational predissociation of the hot 1-naphthol.S levels is detected by a third time-delayed laser by resonant two photon ionization (R2PI) at "hot" vibronic transitions that lie close to the $0_{0}^{0}$ band of the $S_{0} \rightarrow S_{1}$ transition. This triply resonant method is abbreviated as SEP-R2PI; ${ }^{13,31-36,38,42}$ a scheme is shown in Fig. S1 of the supplementary material.

Two frequency-doubled tunable dye lasers (Lambda Physik FL2002 and FL3002, 310-330 nm range in the UV) were employed as pump and dump lasers with UV pulse energies of $\sim 0.2$ and $\sim 2 \mathrm{~mJ} /$ pulse. Both dye lasers were pumped by the same frequency-doubled Nd:YAG laser (Quanta Ray DCR3). The probe dye laser (Lambda Physik LPD 3000, $0.2-0.3 \mathrm{~mJ} /$ pulse in the UV) was pumped by a frequencydoubled Continuum Surelite II Nd:YAG. The dye-laser wavelengths and bandwidths $\left(0.3-0.4 \mathrm{~cm}^{-1}\right)$ before frequency doubling were monitored using a HighFinesse WS6 wavemeter. The probe laser was time-delayed between 1.1 and $3 \mu \mathrm{s}$ relative to the pump and dump lasers and crossed the molecular beam 1-3 mm downstream of these lasers to compensate for the $\sim 950 \mathrm{~m} / \mathrm{s}$ mean speed of the molecular beam. Other experimental details were reported previously. ${ }^{35,36,38}$

Resonant two-photon ionization (R2PI) spectra, dump spectra, and probe spectra were recorded by monitoring the mass-separated ion signals of the respective complexes. Isomeric complexes of the same mass were identified and differentiated using UV/UV holeburning spectroscopy. In this technique, an intense UV laser $(\sim 1 \mathrm{~mJ} / \mathrm{pulse})$ is fixed at the electronic origin $\left(0_{0}^{0}\right.$ band) of a given $1 \mathrm{NpOH} \cdot \mathrm{S}$ isomer, thereby depleting the $v^{\prime \prime}=0$ vibrational ground state of this isomer. A second tunable UV laser is scanned over the region of interest and yields a one-color R2PI spectrum. The $0_{0}^{0}$ and vibronic bands originating from the vibrational ground-state of the depleted isomer can be identified by their reduced intensities, compared to the same scan without the UV hole-burning laser.

Dispersed fluorescence spectra of the $1 \mathrm{NpOH} \cdot n$-alkane complexes were measured by exciting at the respective $0_{0}^{0}$ bands, see below. The emitted fluorescence was collected with UV fused silica optics and dispersed with a high-resolution $1.5 \mathrm{~m}$ scanning monochromator (SOPRA UHRS F1500, $1800 \mathrm{l} / \mathrm{mm}$ grating employed in second order). The slit width of $200 \mu \mathrm{m}$ is equivalent to a spectral bandpass of $3 \mathrm{~cm}^{-1}$. 


\section{B. Theoretical methods}

The minimum-energy structures and harmonic vibrational frequencies of the $1 \mathrm{NpOH} \cdot n$-alkane complexes were calculated using three dispersion-corrected density functional methods. The B97-D3 ${ }^{21}$ and B3LYP-D3 ${ }^{27}$ methods were employed with the def2-TZVPP basis set using TURBOMOLE 7.0. For comparison, we employed the Chai-Gordon long-range and dispersion-corrected $\omega \mathrm{B} 97 \mathrm{X}-\mathrm{D}$ functional, ${ }^{23}$ as implemented in Gaussian $09,{ }^{43}$ using the $6-31++\mathrm{G}(\mathrm{d}, \mathrm{p})$ basis set. The latter two methods gave good results in studies of large $\pi$-stacked complexes. ${ }^{44,45}$ All structure optimizations were unconstrained. The binding energies $D_{e}$ were calculated by subtracting the total energies of 1-naphthol and of the $n$-alkane (both optimized at their respective isolated-molecule geometries) from the total energy of the 1-naphthol. $n$-alkane complex at its optimized minimumenergy geometry. The Boys-Bernardi counterpoise (CP) correction for the basis set superposition error was used for the $\omega \mathrm{B} 97 \mathrm{X}-\mathrm{D}$ calculation. The $\mathrm{CP}$ correction is not recommended if the D3 method is used ${ }^{21}$ and was thus not performed for the B97-D3 and B3LYP-D3 calculations.

The harmonic frequencies and vibrational zero point energies (VEEPS) of the monomers and complexes were calculated with all three DFT methods at the same level as the optimized structures. The dissociation energies $D_{0}$ were then calculated as $D_{0}=D_{e}-\triangle \mathrm{ZPE}$, using the change in vibrational zeropoint energies $(\triangle \mathrm{VZPEs})$, which is given by $\triangle \mathrm{VZPE}=\mathrm{VZPE}$ (complex) - VZPE (1NpOH) - VZPE (n-alkane).

\section{RESULTS}

\section{A. R2PI spectra of 1-naphthol-alkane complexes}

The one-color resonant two-photon ionization spectra of 1-naphthol and of the $n$-alkane complexes from methane to $n$-butane are shown in Fig. 1 . The $S_{0} \rightarrow S_{1}$ electronic origins of the complexes are shifted to a slightly lower wavenumber than the $0_{0}^{0}$ band of 1-naphthol, which is at $31455.9 \mathrm{~cm}^{-1}$. The spectral shifts $\delta \tilde{v}$ between the $S_{0} \rightarrow S_{1}$ electronic origins of 1-naphthol and the 1-naphthol.S complexes are very small, between $\delta \tilde{v}=-0.5 \mathrm{~cm}^{-1}$ for $n$-butane and $\delta \tilde{v}=-14.6$ $\mathrm{cm}^{-1}$ for methane. Since the $S_{0} \rightarrow S_{1}$ electronic excitation of the complex is essentially localized on the $1 \mathrm{NpOH}$ chromophore, the dissociation limits of the $S_{0}$ and $S_{1}$ states lead to $S_{0}$ and $S_{1}$ electronic states of the 1-naphthol moiety and to the electronic ground state of the $n$-alkane moiety; see also Fig. S1 of the supplementary material. Via a Born-Haber-type thermodynamic cycle, one can show that the spectral shift corresponds to the difference of the ground- and excited-state dissociation energies, $\delta \tilde{v}=D_{0}\left(S_{0}\right)-D_{0}\left(S_{1}\right) \cdot{ }^{46-48}$ Such small spectral shifts (small changes of the dissociation energy) are typical for Face complexes of nonpolar molecules. ${ }^{35-38}$ The low-frequency bands toward the high-energy (blue) side of the R2PI spectra in Figs. 1(b)-1(e) are $S_{1}$ state intermolecular vibrational fundamentals, overtones, and combination bands.

All complexes were investigated by UV/UV holeburning. For the complexes with $\mathrm{S}=$ methane, ethane, and propane, all of the sharp bands in the respective R2PI spectra belong to the

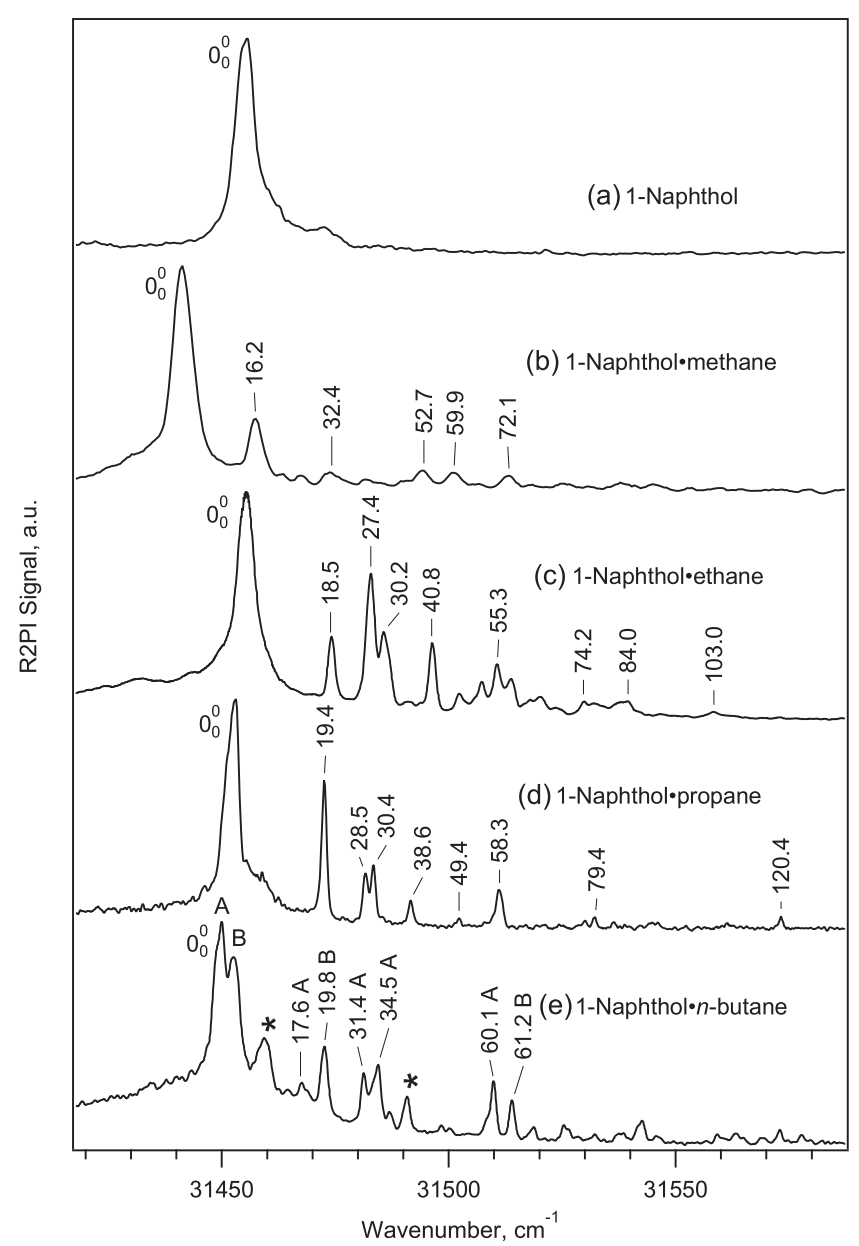

FIG. 1. One-color resonant-two-photon ionization spectra of (a)1-naphthol and its complexes with (b) methane, (c) ethane, (d) propane, and (e) $n$-butane. The butane spectrum consists of subspectra of three $n$-butane isomers (A, B, and C), as shown in Fig. 3. The $S_{1}$ intermolecular vibronic excitations are labeled with their vibrational energies; for assignments, see Sec. IV C.

same ground-state isomer. For the $1 \mathrm{NpOH}$-propane complex, we compare the R2PI spectrum in Fig. 2(a) to the UV/UV holeburning spectrum in Fig. 2(b). Subtracting spectrum (b) from spectrum (a) yields the unstructured spectrum shown in Fig. 2(c), whose broad maximum is shifted to the red of the $0_{0}^{0}$ band. We attribute this broad feature to a residual population of incompletely cooled $1 \mathrm{NpOH}$-propane complexes. The broad spectrum is the superposition of the hot-band transitions out of the excited $\left(v^{\prime \prime}>0\right)$ ground-state vibrational levels.

The R2PI spectrum of $1 \mathrm{NpOH} \cdot n$-butane is more complex than those of the smaller alkanes; see Fig. 1(e). UV holeburning was employed at the two most intense bands marked $A$ and B (at $31449.9 \mathrm{~cm}^{-1}$ and $31452.7 \mathrm{~cm}^{-1}$ ); see the downwardpointing arrows in Fig. 3(a). The resulting UV/UV-holeburned spectra are different and are shown in Figs. 3(b) and 3(c). We thus assign these spectra to different isomers that we denote "A" and "B," correspondingly. After subtraction of the UV-holeburned spectra of the A and B isomers from the total R2PI spectrum, Fig. 3(a), several weak bands remain between 31460-31490 $\mathrm{cm}^{-1}$, which we assign to a higher-energy isomer C. This isomer could not be usefully separated by UV-holeburning since its $0_{0}^{0}$ band overlaps with the more 


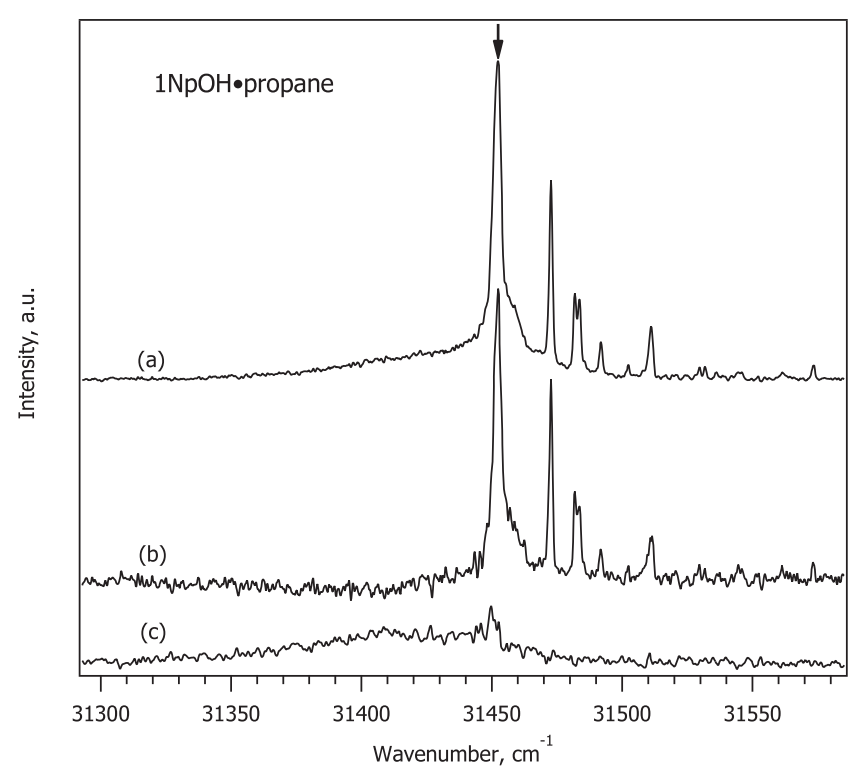

FIG. 2. R2PI and UV/UV-holeburning spectra of 1-naphthol-propane: (a) one-color R2PI spectrum and (b) UV-holeburned spectrum showing that all sharp bands belong to a single isomer. (c) The remaining difference spectrum.

intense vibronic band structure of isomers $\mathrm{A}$ and $\mathrm{B}$. Because of its low intensity, isomer $\mathrm{C}$ was not further investigated. To the red side of the $0_{0}^{0}$ band of isomer $\mathrm{A}$, one again observes an unstructured and broad feature; this is assigned to a residual population of incompletely cooled complexes, as discussed for the propane complex. The relative weakness of the broad

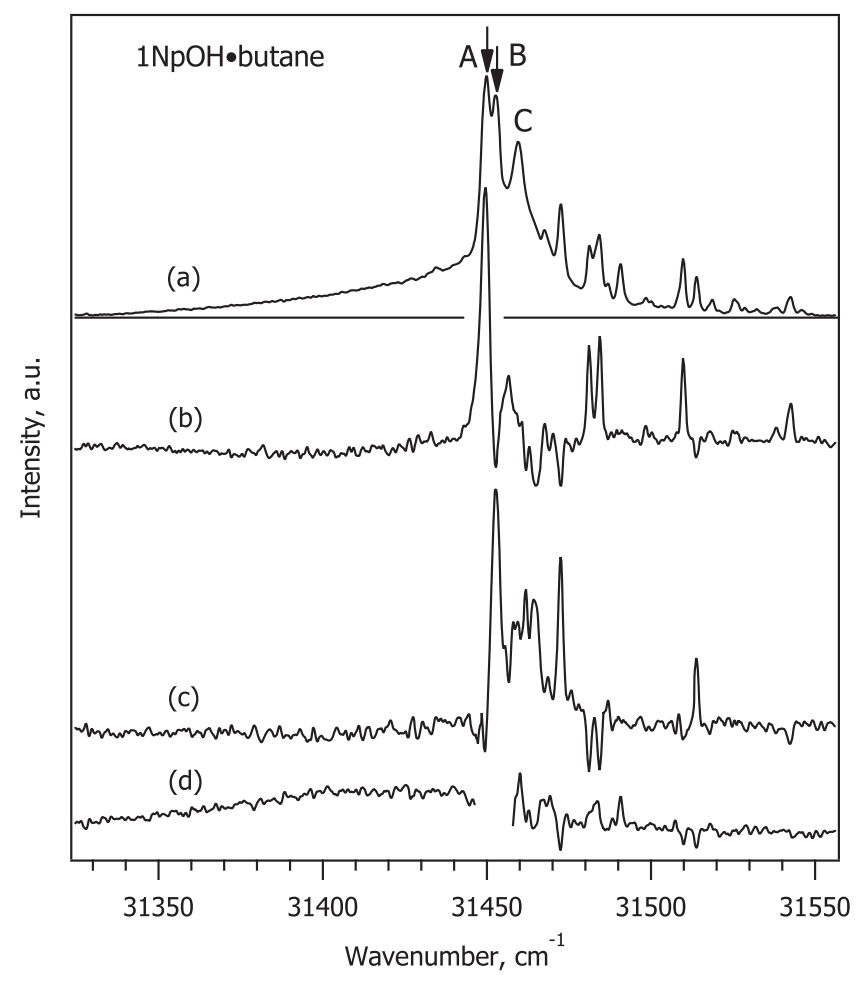

FIG. 3. (a) Resonant two-photon ionization spectrum of 1-naphthol-butane (the same as in Fig. 1). (b) UV/UV holeburned spectrum of isomer A (UV holeburning laser at $31449.9 \mathrm{~cm}^{-1}$, as indicated by the vertical arrow). (c) UV/UV holeburning spectrum of isomer B (UV-holeburning laser at $31452.7 \mathrm{~cm}^{-1}$, indicated by the arrow). (d) Remaining spectrum after the spectra of isomers A and B have been subtracted. features implies that the Edge $\rightarrow$ Face isomerization barriers are low so that efficient relaxation to the more stable Face isomers occurs.

\section{B. Experimental dissociation energies}

The ground state intermolecular dissociation energies $D_{0}\left(S_{0}\right)$ of the 1-naphthol-alkane complexes are bracketed between two ground state $\left(S_{0}\right)$ vibrational levels in the $S_{1} \rightarrow S_{0}$ spectra: The lower limit to $D_{0}\left(S_{0}\right)$ is given by the highestenergy $S_{0}$ state level that does not vibrationally predissociate. This level is observed via the highest-wavenumber $S_{1} \rightarrow S_{0}$ stimulated downward transition in a hot-band probed SEPR2PI spectrum; see Sec. II A. The upper limit to $D_{0}$ is given by the next higher energy vibrational level of the $S_{0}$ state complex that lies above the limit to vibrational predissociation (VP). This level (and many higher-energy $S_{0}$ state vibrational levels above the $D_{0}$ limit) is observable by spectroscopies that operate on a 1-10 ns time scale (much) shorter than the typical VP time scale. These are (1) dispersed fluorescence spectroscopy, (2) "dump" spectroscopy, or (3) origin-probed SEP-R2PI spectroscopy; these methods report on the $S_{0}$ state vibrational levels in a similar way. Which of these spectra exhibits the highest signal/noise ratio depends on the $S_{1}$ state fluorescence quantum yield of the $1 \mathrm{NpOH} \cdot \mathrm{S}$ complex and on the vibronic band intensities of the dump and origin-probed SEP-R2PI spectra. The latter two reflect the efficiency of the stimulated-emission process, which depends not only on the optical vibronic band intensity (Franck-Condon factor, as for the fluorescence emission) but also on the $S_{0}$-state intramolecular vibrational redistribution (IVR) rate. The $S_{0}$ IVR rates may vary considerably depending on the target vibrational level. Thus, while the vibronic band positions are identical in all three spectra, the band intensities of the dump and hotband probed SEP spectra may differ substantially from those of the fluorescence spectrum and from each other. In the following, we will show the spectrum with the highest signal/noise (S/N) ratio for comparison with the hot-band probed SEP-R2PI spectrum. The $D_{0}$ values in ground and $S_{1}$ electronic states are collected in Table I.

\section{1-naphthol.propane}

In Fig. 4(a), we show the hot-band-probed SEP-R2PI spectrum of the propane complex, measured at the peak of a broad feature $54 \mathrm{~cm}^{-1}$ below the $0_{0}^{0}$ band. The highest-energy band in this spectrum is observed at $1390 \mathrm{~cm}^{-1}$ relative to the $0_{0}^{0}$ band. Figure 4(b) shows the dump spectrum, which also exhibits a strong band at $1390 \mathrm{~cm}^{-1}$. The following band in the dump spectrum at $1403 \mathrm{~cm}^{-1}$ is not observed in trace (a), so it represents the upper limit of $D_{0}\left(S_{0}\right)$. We take the $D_{0}\left(S_{0}\right)$ of 1-naphthol-propane complex as the average of the two band positions and the bracketing uncertainty to be half the difference of the wavenumbers of the two band. Thus, $D_{0}\left(S_{0}\right)$ is bracketed as $1397 \pm 7 \mathrm{~cm}^{-1}$. The true value may lie anywhere in this range, with equal probability.

\section{1-naphthol·n-butane}

The ground-state dissociation energies were measured for both isomers $\mathrm{A}$ and $\mathrm{B}$; the respective spectra are shown 
TABLE I. Experimental ground- and excited-state dissociation energies $D_{0}\left(S_{0}\right)$ and $D_{0}\left(S_{1}\right)$ and spectral shifts of the $0_{0}^{0}$ bands $\delta \tilde{v}$ of the 1 -naphthol $\cdot n$-alkane complexes. The $D_{0}$ may lie anywhere within the bracketed interval with equal probability.

\begin{tabular}{|c|c|c|c|c|c|}
\hline \multirow[b]{2}{*}{ Admolecule S } & \multicolumn{2}{|c|}{$D_{0}\left(S_{0}\right)$} & \multicolumn{2}{|c|}{$D_{0}\left(S_{1}\right)$} & \multirow[b]{2}{*}{$\delta \tilde{v}^{\mathrm{a}} \mathrm{cm}^{-1}$} \\
\hline & $\mathrm{cm}^{-1}$ & $\mathrm{~kJ} / \mathrm{mol}$ & $\mathrm{cm}^{-1}$ & $\mathrm{~kJ} / \mathrm{mol}$ & \\
\hline Methane & $667 \pm 46$ & $7.98 \pm 0.55$ & $682 \pm 46$ & $8.15 \pm 0.5$ & -14.6 \\
\hline Ethane & $1207 \pm 30$ & $14.44 \pm 0.36$ & $1207 \pm 30$ & $14.43 \pm 0.36$ & -0.5 \\
\hline Propane & $1397 \pm 7$ & $16.71 \pm 0.08$ & $1400 \pm 7$ & $16.74 \pm 0.08$ & -3 \\
\hline$n$-butane, isom. A & $1715 \pm 8$ & $20.52 \pm 0.10$ & $1721 \pm 8$ & $20.59 \pm 0.10$ & -6 \\
\hline$n$-butane, isom. B & $1693.5 \pm 4.5$ & $20.26 \pm 0.05$ & $1696.5 \pm 5$ & $20.25 \pm 0.06$ & -3 \\
\hline
\end{tabular}

${ }^{\text {a }}$ Spectral shift relative to the $0_{0}^{0}$ band of trans-1-naphthol at $31455.9 \mathrm{~cm}^{-1}$.

in Figs. 5 and 6. For isomer A, the highest-wavenumber band in the hot-band-detected SEP spectrum is observed at $1707 \mathrm{~cm}^{-1}$, while the next higher band in the origin-detected SEP spectrum at $1723 \mathrm{~cm}^{-1}$, (b), is not observed in Fig. 5(a), nor are any of the following bands. The $D_{0}\left(S_{0}\right)$ value for isomer A is thus bracketed as $D_{0}\left(S_{0}\right)=1715 \pm 8 \mathrm{~cm}^{-1}$.

The hot-band SEP spectrum of isomer B in Fig. 6(a) shows a clear last band at $1689 \mathrm{~cm}^{-1}$. No higher-wavenumber bands appear in Fig. 6(a), while the next higher band in Fig. 6(b) at $1698 \mathrm{~cm}^{-1}$ has no counterpart in Fig. 6(a). This brackets the dissociation energy between 1689 and $1698 \mathrm{~cm}^{-1}$, giving $D_{0}\left(S_{0}\right)=1693.5 \pm 4.5 \mathrm{~cm}^{-1}$.

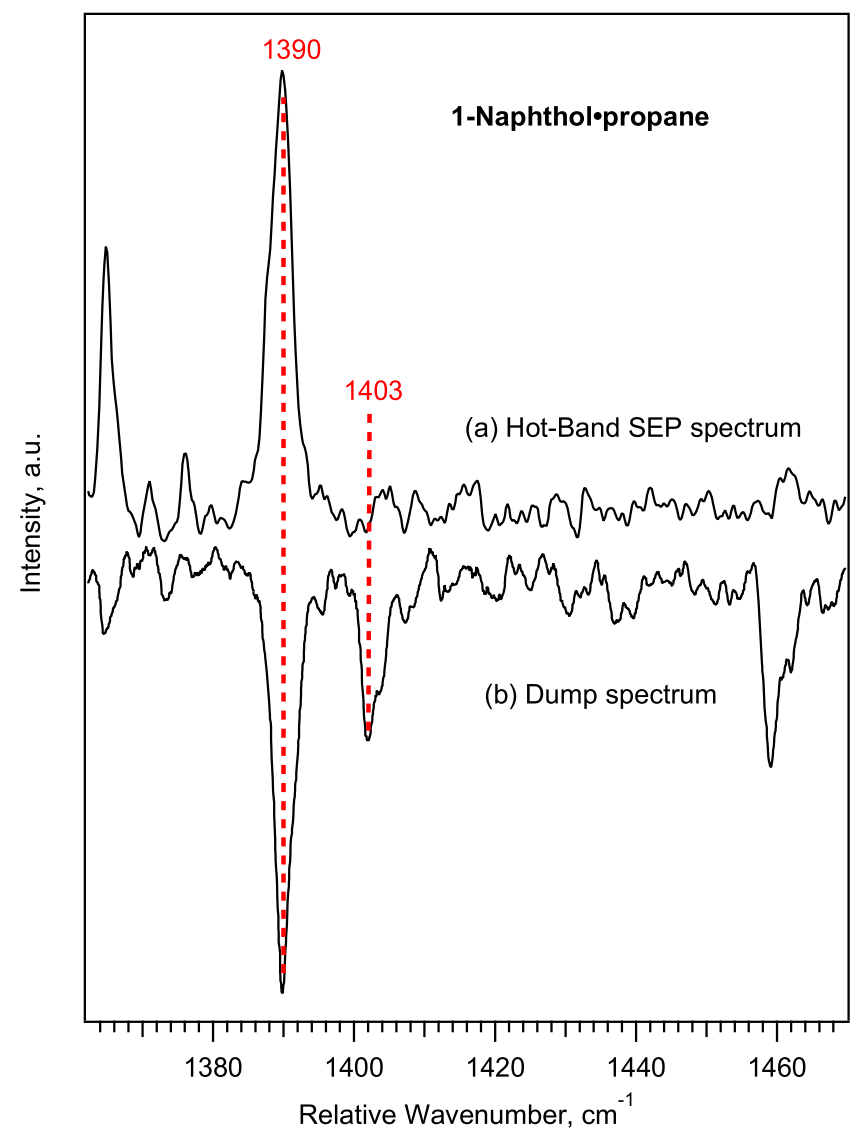

FIG. 4. (a) Hot band $\left(0_{0}^{0}-54 \mathrm{~cm}^{-1}\right)$ probed SEP-R2PI spectrum of $1 \mathrm{NpOH}$-propane and (b) origin probed SEP-R2PI spectrum. The $D_{0}\left(S_{0}\right)$ is bracketed by the vertical red dashed lines at 1390 and $1403 \mathrm{~cm}^{-1}$. The horizontal axis is the difference between the pump frequency at the $0_{0}^{0}$ band $\left(31452.9 \mathrm{~cm}^{-1}\right)$ and the dump laser.

\section{1-naphthol.methane}

The hot-band SEP spectrum of $1 \mathrm{NpOH} \cdot \mathrm{methane}$ was recorded at a feature $52 \mathrm{~cm}^{-1}$ to the red of the $0_{0}^{0}$ band and is shown in Fig. 7(a). Since the R2PI spectrum of the methane complex is shifted well to the red of that of 1-naphthol, the $1 \mathrm{NpOH} \cdot m e t h a n e S_{0} \rightarrow S_{1}$ electronic origin has no accidental overlap with the $S_{0} \rightarrow S_{1}$ origin of bare $1 \mathrm{NpOH}$, so the former can be cleanly excited. Thus, the electronic $S_{1} \rightarrow S_{0}$ dispersed fluorescence spectrum of $1 \mathrm{NpOH} \cdot$ methane excited at the $0_{0}^{0}$ band exhibits an excellent $\mathrm{S} / \mathrm{N}$ ratio. It is larger than that of the origin-detected SEP spectrum in the spectral range of interest, so we show the former in Fig. 7(b). The highestwavenumber band in the hot-band SEP trace is at $879 \mathrm{~cm}^{-1}$ and the next higher energy band in the fluorescence spectrum is at $926 \mathrm{~cm}^{-1}$, which would seem to set $D_{0}\left(S_{0}\right)$ between 879 and $926 \mathrm{~cm}^{-1}$. However, the 713 and $879 \mathrm{~cm}^{-1}$ bands in trace (a) are five to ten times weaker than the respective bands in trace (b). Conversely, the bands in trace (a) up to $621 \mathrm{~cm}^{-1}$ are between two and ten times stronger than the corresponding bands in trace (b). In other words, the 713 and $879 \mathrm{~cm}^{-1}$ bands in the hot-band SEP spectrum are abnormally weak. We therefore propose that the 713 and $879 \mathrm{~cm}^{-1}$ bands in trace (a) arise from vibrational levels that undergo VP with a longer

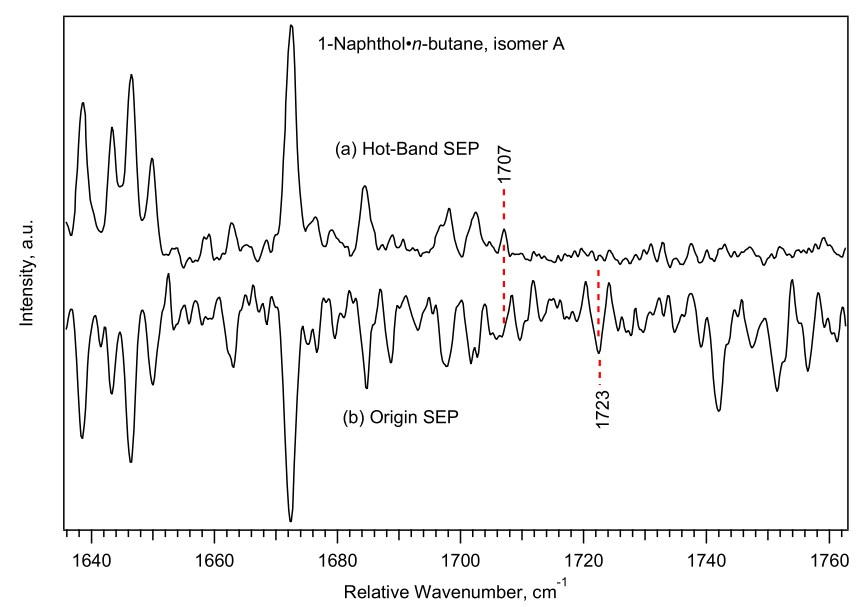

FIG. 5. (a) Hot band $\left(0_{0}^{0}-61 \mathrm{~cm}^{-1}\right)$ probed SEP-R2PI spectrum of isomer A of $1 \mathrm{NpOH} \cdot n$-butane and (b) origin-probed SEP-R2PI spectrum. The $D_{0}\left(S_{0}\right)$ is bracketed by the vertical red dashed lines at 1707 and $1723 \mathrm{~cm}^{-1}$. The horizontal axis is the difference between the pump frequency at the $0_{0}^{0}$ band $\left(31449.9 \mathrm{~cm}^{-1}\right.$ ) and the dump laser. 


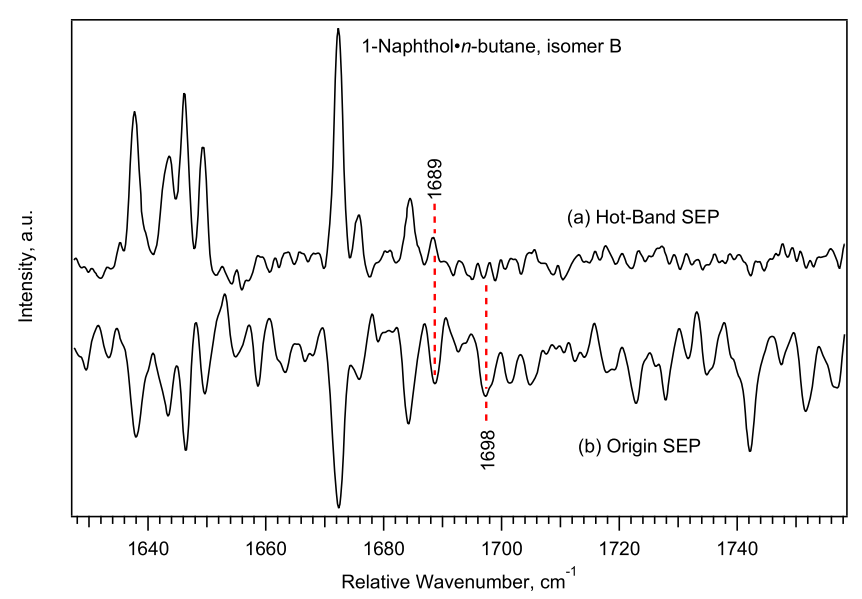

FIG. 6. (a) Hot band $\left(0_{0}^{0}-63 \mathrm{~cm}^{-1}\right)$ probed SEP-R2PI spectrum of isomer B of $1 \mathrm{NpOH} \cdot n$-butane and (b) origin-probed SEP-R2PI spectrum. The $D_{0}\left(S_{0}\right)$ is bracketed by the vertical red dashed lines at 1689 and $1698 \mathrm{~cm}^{-1}$. The horizontal axis is the difference between the pump frequency at the $0_{0}^{0}$ band (31 $452.7 \mathrm{~cm}^{-1}$ ) and the dump laser.

lifetime than the $3 \mu$ s delays utilized in this experiment. The $621 \mathrm{~cm}^{-1}$ band then corresponds to the highest-energy vibration that is certainly below $D_{0}$, while the abnormally weak $713 \mathrm{~cm}^{-1}$ level very probably lies above $D_{0}\left(S_{0}\right)$ and sets the upper limit to $D_{0}\left(S_{0}\right)$. To allow detailed comparison, we show expanded traces of the two spectra in Figs. 7(a) and 7(b). This interpretation of the data implies that $D_{0}\left(S_{0}\right)=667 \pm 46 \mathrm{~cm}^{-1}$ for the 1-naphthol-methane complex.

\section{1-NpOH.ethane}

Figure 8(a) shows the hot-band-detected SEP-R2PI spectrum of 1-naphthol-ethane. The signal was detected at a hotband feature $66 \mathrm{~cm}^{-1}$ below the $0_{0}^{0}$ band. This spectrum closely mirrors the origin-probed SEP spectrum shown in Fig. 8(b) up to the band at $1177 \mathrm{~cm}^{-1}$. Note that all bands in Fig. 8(a) below $1177 \mathrm{~cm}^{-1}$ have similar or larger intensities compared to those in Fig. 8(b). We therefore propose that the $1177 \mathrm{~cm}^{-1}$ vibrational level corresponds to the lower $D_{0}\left(S_{0}\right)$ limit. The following bands at $1192 \mathrm{~cm}^{-1}, 1237$ and $1281 \mathrm{~cm}^{-1}$, and further weak features in the $1335-1370 \mathrm{~cm}^{-1}$ region in trace (a) are above the noise but are considerably

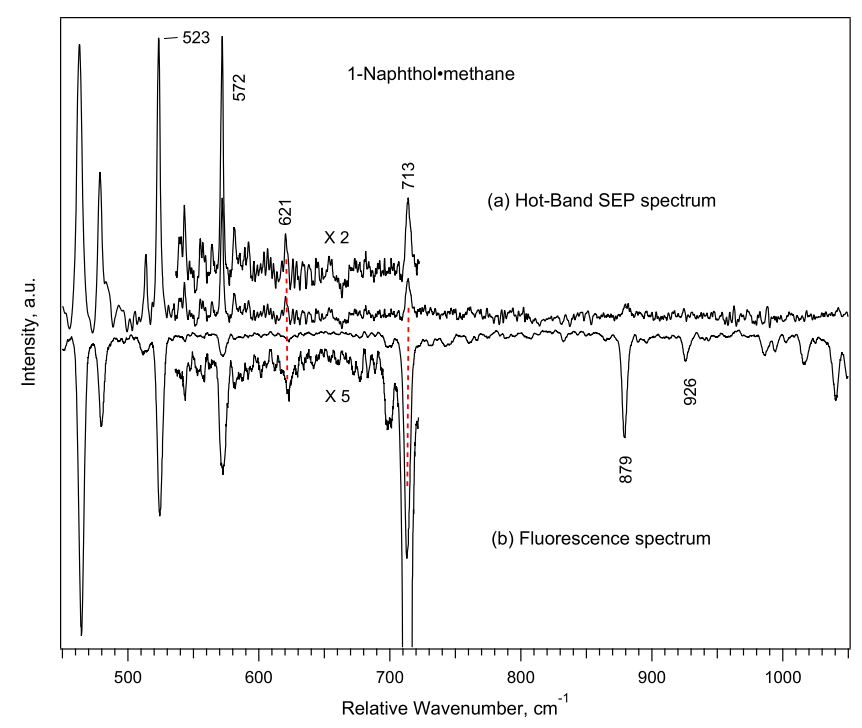

FIG. 7. (a) Hot-band probed SEP-R2PI spectrum and (b) dispersed fluorescence spectrum of $1 \mathrm{NpOH} \cdot$ methane. The upper trace was probed at $0_{0}^{0}-66 \mathrm{~cm}^{-1}$. The horizontal axis is the difference between the pump laser at the $0_{0}^{0}$ band $\left(31445.4 \mathrm{~cm}^{-1}\right)$ and the dump laser wavenumber. Vertically expanded traces $(2 \mathrm{x}, 5 \mathrm{x})$ are included in the critical region between 530 and $720 \mathrm{~cm}^{-1}$. We propose that the $D_{0}\left(S_{0}\right)$ is bracketed by the two vertical red dashed lines at 621 and $713 \mathrm{~cm}^{-1}$.

weaker than the corresponding bands in trace (b). Similar to the methane complex discussed above, we propose that the weak bands possibly starting at $1192 \mathrm{~cm}^{-1}$ but certainly above $1237 \mathrm{~cm}^{-1}$ in Fig. 8(a) arise from long-lived vibrational levels that decay with a longer lifetime than the $3 \mu$ s used in our experiments; see Sec. III D. To be on the safe side, we propose that the vibronic band at $1237 \mathrm{~cm}^{-1}$ marks the upper limit for $D_{0}\left(S_{0}\right)$.

\section{Comparisons of experimental dissociation energies}

In Fig. 9, we plot the experimental $S_{0}$ state dissociation energies of the 1-naphthol- $n$-alkane complexes vs. the experimental average electronic polarizability $\bar{\alpha}$ of the respective $n$-alkane moieties. ${ }^{49}$ For comparison, we have included the $D_{0}\left(S_{0}\right)$ values of the noble-gas complexes with $\mathrm{Ne}, \mathrm{Ar}$,

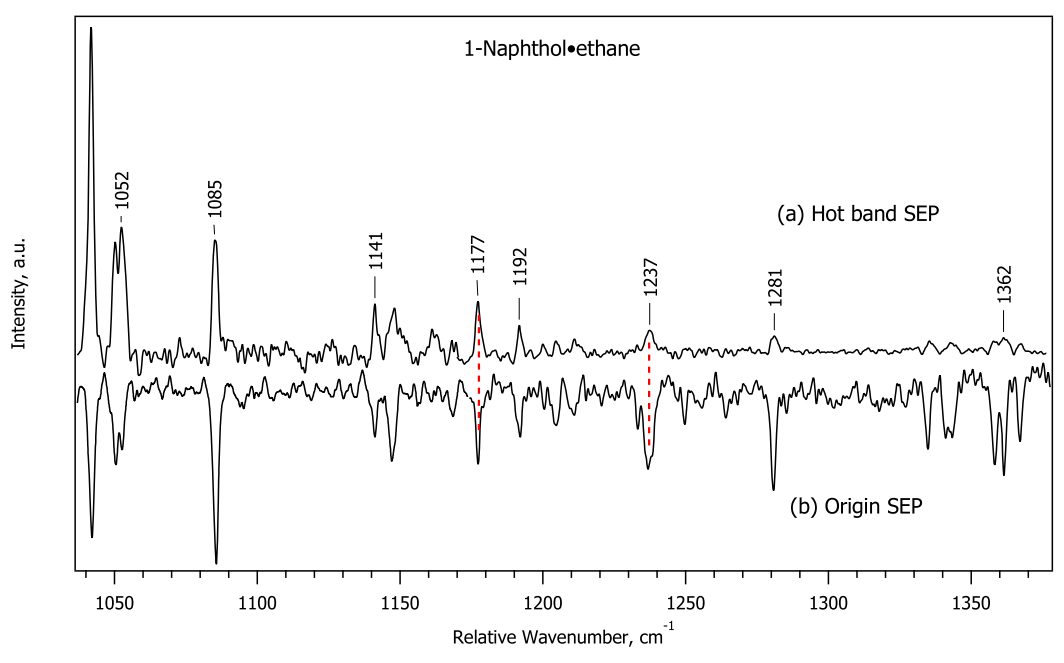

FIG. 8. (a) Hot band $\left(0_{0}^{0}-66 \mathrm{~cm}^{-1}\right)$ probed SEPR2PI spectrum and (b) origin-probed SEP spectrum of $1 \mathrm{NpOH}$-ethane. We propose that the $D_{0}\left(S_{0}\right)$ is bracketed by the vertical red dashed lines at 1177 and 1237 $\mathrm{cm}^{-1}$, as described in the text. The horizontal axis is the difference between the pump frequency at the $0_{0}^{0}$ band (31 $445.4 \mathrm{~cm}^{-1}$ ) and the dump laser. 


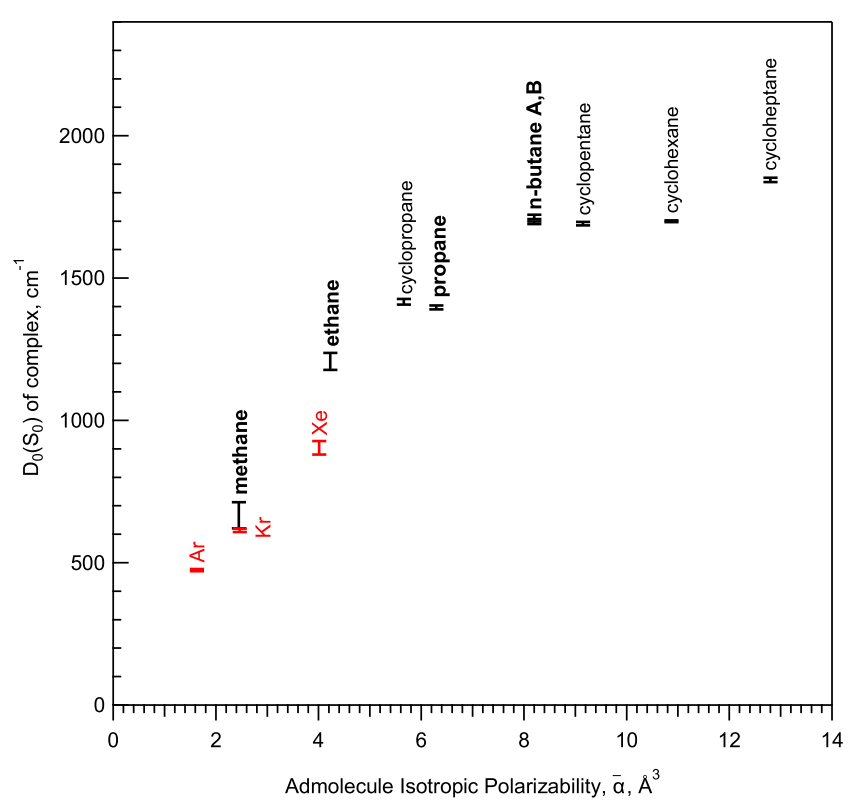

FIG. 9. Experimental SEP-R2PI ground-state dissociation energies $D_{0}\left(S_{0}\right)$ of the 1-naphthol. $\mathrm{S}$ complexes with $\mathrm{S}=n$-alkane (labeled in bold font), $\mathrm{S}=$ cycloalkane, and $\mathrm{S}=$ noble gas (labeled in red) plotted vs. the average electronic polarizability $\bar{\alpha}$ of the adsorbate atom or molecule.

$\mathrm{Kr}$, and $\mathrm{Xe}$ and of several cycloalkanes, all of which form Face complexes. ${ }^{36,37}$ For the smaller solvents up to propane, the experimental $D_{0}\left(S_{0}\right)$ values correlate roughly linearly with the average electronic polarizability $\bar{\alpha}$, but above propane, the slope of the correlation decreases abruptly.

This plateau is not expected from the Eisenshitz-London atom-atom model for dispersion, which predicts a continuation of the quasi-linear trend. As discussed in Ref. 36 for cyclopentane and cyclohexane, for larger $\mathrm{S}$ molecules, the three-dimensional structure of the molecule becomes important and dispersion interactions can no longer be reduced to a single molecular parameter like polarizability. Instead, the atoms of $\mathrm{S}$ which are in closest contact with the naphthol Face contribute much more to dispersive binding than those which are further away. In the case of $n$-butane, for example, Fig. 10 shows that four hydrogen atoms are pointing away from the naphthol and therefore add relatively little to the binding energy. One end of the $n$-butane chain is also hanging over the side of the naphthol in both structures. The corresponding methyl group thus contributes less than the methyl group which is in full contact with electron-rich ring. As $\mathrm{S}$ molecules increase in size, dispersive interactions will become geometrically limited by the possible contact surface between $\mathrm{S}$ and naphthol. Another way in which molecules deviate from the Eisenshitz-London model is that, except for spherical-top molecules such as methane, the molecular polarizability is a tensor. While the off diagonal elements of the polarizability tensor are zero (or very close to zero), the diagonal elements may differ strongly. For example, the fractional polarizability anisotropies of the $n$-alkanes range from $\alpha_{\text {aniso }} / \bar{\alpha}=10 \%$ for ethane to $\alpha_{\text {aniso }} / \bar{\alpha}=25 \%$ for trans $-n$ butane; for naphthalene, $\alpha_{\text {aniso }} / \alpha_{\text {iso }}=76 \%$ and is even larger for 1-naphthol. Thus the average polarizability $\bar{\alpha}$ is not a welldefined variable for gauging dispersive molecule-molecule

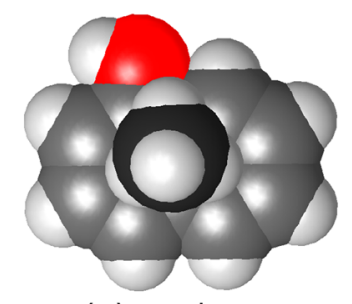

(a) methane

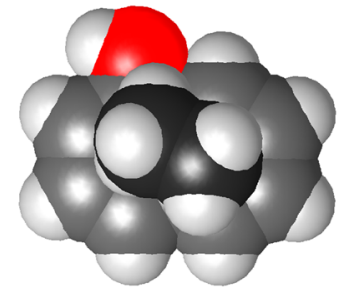

(b) ethane

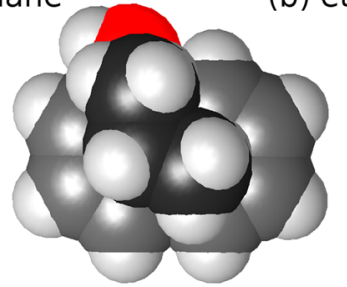

(c) propane

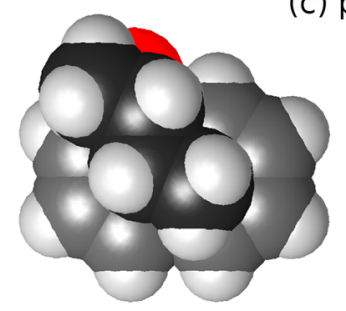

(d) n-butane Face A

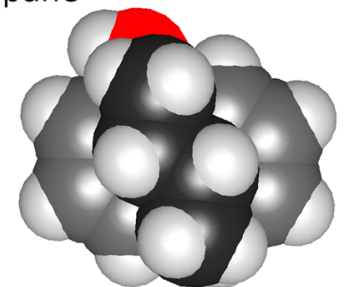

(e) n-butane Face C
FIG. 10. The B97-D3/def2-TZVPP optimized structures of the 1-naphthol Face complexes with (a) methane, (b) ethane, (c) propane (Face 5 isomer), (d) $n$-butane (most stable isomer Face C), and (e) $n$-butane (second most stable isomer Face $\mathrm{A}$ ). The $\mathrm{C}$ atoms of the alkanes are color-coded in black and those of 1-naphthol are color-coded in gray.

interactions and should be viewed more as an ordering parameter.

\section{Calculated structures}

We discuss the B97-D3 calculated structures, but note that the B3LYP-D3 and $\omega$ B97X-D calculated structures are similar. Figure 10 shows the B97-D3 structures of the 1-naphthol Face complexes with methane, ethane, propane, and the two most stable isomers of the $n$-butane complex, denoted Face $\mathrm{C}$ and Face A.

All DFT methods predict a single Face minimum for the $1 \mathrm{NpOH} \cdot m e t h a n e$ and $1 \mathrm{NpOH} \cdot$ ethane complexes. For $1 \mathrm{NpOH} \cdot$ propane, they predict five different Face isomers and one Edge structure. This Edge structure is shown in Fig. S3 of the supplementary material. The largest binding energy $\left(D_{e}=-19.68 \mathrm{~kJ} / \mathrm{mol}\right)$ was calculated for the Face 5 isomer; the well depth of the Face 3 isomer is very close $\left(D_{e}=-19.47\right.$ $\mathrm{kJ} / \mathrm{mol}$ ) and the Face 1 and Face 2 isomers lie within $1 \mathrm{~kJ} / \mathrm{mol}$ of Face 3. The well depth of the propane Edge isomer is $D_{e}=-12.67 \mathrm{~kJ} / \mathrm{mol}, \sim 6 \mathrm{~kJ} / \mathrm{mol}$ smaller than those of the Face isomers.

Because of this much smaller binding energy, and since no sharp vibronic bands of Edge isomers were experimentally observed, we did not optimize any Edge structures for the $n$-butane complex. The calculations predict five different Face minima with $n$-butane in its trans conformation and eight Face isomers with the $n$-butane moiety in its higher-energy gauche rotamer. As might be expected, the 
trans-rotamer complexes are more strongly bound than the gauche-rotamers. The two most stable trans-rotamer complexes are close in binding energy, trans Face $A$ with $D_{e}=-24.10 \mathrm{~kJ} / \mathrm{mol}$ and trans Face $C$ with $D_{e}=-23.90$ $\mathrm{kJ} / \mathrm{mol}$. Four of the trans rotamer Face structures (Face $A-$ Face $D$ ) have larger $D_{e}$ s than the most stable gauche rotamer cis-iso- $T 2\left(D_{e}=-20.60 \mathrm{~kJ} / \mathrm{mol}\right)$.

The Cartesian coordinates of the ground states of all complexes as well as the corresponding monomers optimized with B97-D3/def2-TZVPP are given in Tables S1-S14 of the supplementary material). The calculated Face isomer structures of the $1 \mathrm{NpOH} \cdot$ cycloalkane complexes that are also discussed below have been previously reported. ${ }^{35}$

Figure 10(a) shows that the $\mathrm{CH}_{4}$ moiety in the complex sits closely above the center of the naphthalene ring but shifted slightly toward the $\mathrm{OH}$ group. This structure is similar to those of $1 \mathrm{NpOH} \cdot \mathrm{Kr}$ and $1 \mathrm{NpOH} \cdot \mathrm{Xe}$ complexes. ${ }^{37}$ Figure 10(b) shows that the long axis of the ethane moiety is oriented along the naphthalene long axis, with two $\mathrm{H}$ atoms on neighboring carbon atoms pointing down toward the centers of the aromatic rings. Figures 10(c)-10(e) shows that the long axes of the propane and $n$-butane moieties are oriented diagonally with respect to the naphthalene substrate. This orientation allows two of the $\mathrm{H}$ atoms on neighboring $\mathrm{C}$ atoms to point down into the centers of the benzene rings. In complexes of naphthalene, there would be two degenerate diagonal Face orientations for propane and the two $n$-butane isomers; since the 1-naphthol substrate favors the admolecule orientations shown in Figs. 10(c)-10(e), we conclude that the alkane chains are maximizing the dispersive interactions of one of their terminal methyl groups with the $\mathrm{OH}$ group of the substrate. A further reason why this diagonal is favored may be the electrostatic naphthol-dipole $\leftrightarrow$ alkane-quadrupole interaction.

In reality, the $\mathrm{CH}_{4}$ moiety in the $1 \mathrm{NpOH} \cdot$ methane complex is not rigid, as Fig. 10(a) implies. The translationrotational-vibrational cooling of the $\mathrm{CH}_{4}$ during the supersonic expansion is essentially complete within $\sim 30 \mathrm{~mm}$ from the nozzle exit, i.e., within $\sim 30 \mu$ s. This is $10^{3}-10^{5}$ times faster than typical gas-phase nuclear-spin relaxation rates. Thus, the room-temperature ortho, para, and meta nuclearspin states of methane do not interconvert but remain at the high-temperature relative ratios. Because of restrictions on the nuclear-spin plus rotational state symmetry, jet-cooled $\mathrm{CH}_{4}$ can only cool to the lowest three rotational states $(J=0,1,2)$ with total statistical weights of $5(J=0)$, $9(J=1)$, and $10(J=2) .{ }^{50}$ Consequently, the $1 \mathrm{NpOH} \cdot$ methane complexes are formed as three nuclear-spin isomers. ${ }^{50-52}$ For the structurally related 1-fluoronaphthalene. $\mathrm{CH}_{4}$ and 2-fluoronaphthalene $\cdot \mathrm{CH}_{4}$ complexes, Champagne et al. have found that the $0_{0}^{0}$ and higher vibronic bands of the complex are split by about 0.9 and $0.25 \mathrm{~cm}^{-1}$ into three sub-bands with an intensity ratio of $1: 2: 2$, reflecting the $J=0,1,2$ internalrotation levels of the ortho, para, and meta nuclear-spin states of the $\mathrm{CH}_{4}$ admolecule. ${ }^{50}$ They also performed extensive model calculations of the internal-rotation level structure of fluoronaphthalene $\cdot \mathrm{CH}_{4}$ complexes and concluded that the $\mathrm{CH}_{4}$ moiety exhibits virtually free rotation about two of its axes, only the "top to bottom" rotation being slightly hindered. ${ }^{50}$
We thus expect the 1-naphthol. $\mathrm{CH}_{4}$ complex to exist as an approximate 1:2:2 mixture of ortho, para, and meta nuclearspin isomers. The orientation of the rotational axes in the $J=0,1$, and 2 levels is expected to be nearly isotropic. Since we did not observe any sub-band structure in the R2PI spectrum, see Fig. 1(b), the $J=0 / 1 / 2$ splittings must be smaller than the $\sim 5 \mathrm{~cm}^{-1}$ FWHM of the origin band of 1-naphthol. $\mathrm{CH}_{4}$; thus we could not perform nuclear-spin resolved $D_{0}$ determinations.

A similar situation arises for $1 \mathrm{NpOH}$-ethane, since the ethane moiety exhibits essentially free rotation around its long axis as well as internal-rotation around the $\mathrm{C}-\mathrm{C}$ bond, while adsorbed on the naphthol substrate. Ethane has six nuclearspin/rotational species which cannot interconvert on the experimental time scale. Wilson has shown that these six species divide into two sets; the relative population of these sets only begins to change at temperatures below $90 \mathrm{~K}$. While hindered internal rotation of the methyl groups also takes place in propane and $n$-butane, rotation of the admolecule themselves is strongly hindered.

\section{DISCUSSION}

\section{A. Structures of the 1-naphthol-n-alkane complexes and spectral shifts}

The spectral shift of the $S_{0} \rightarrow S_{1}$ origin band, $\delta \tilde{v}$, has been found to be an indicator of the binding topology of $1 \mathrm{NpOH}$ intermolecular complexes. In the dispersively bound $1 \mathrm{NpOH} \cdot \mathrm{S}$ complexes where $\mathrm{S}$ is a noble-gas or $\mathrm{N}_{2}$, the atoms or the $\mathrm{N}_{2}$ molecule is adsorbed to the Face of the naphthol aromatic system and the spectral shifts are small, between $\delta \tilde{v}=-2 \mathrm{~cm}^{-1}$ for $\mathrm{S}=\mathrm{Ne}$ and $-35 \mathrm{~cm}^{-1}$ for $\mathrm{S}=\mathrm{Xe} .^{37,53}$ Similarly, the Face isomer of $1 \mathrm{NpOH} \cdot$ cyclopropane exhibits a small spectral blue shift of $\delta \tilde{v}=+2 \mathrm{~cm}^{-1}, 35,38$ for $1 \mathrm{NpOH} \cdot$ cyclohexane $\delta \tilde{v}=-1.7 \mathrm{~cm}^{-1}$, and for the cycloheptane complex isomers $\mathrm{A}$ and $\mathrm{B}$ the shifts are $\delta \tilde{v}=-38.5$ and $-32.9 \mathrm{~cm}^{-1}$, close to that of the Xe complex. ${ }^{35,38}$ If the admolecule is $\mathrm{H}$-bonded to the $-\mathrm{OH}$ group of 1-naphthol $\mathrm{OH}$ group, as in the $\mathrm{H}_{2} \mathrm{O}, \mathrm{CH}_{3} \mathrm{OH}$, and $\mathrm{NH}_{3}$ complexes, the spectral red shifts are much larger, being $\delta \tilde{v}=-145,-158$, and $-236 \mathrm{~cm}^{-1}$, respectively, ${ }^{33,34}$ and the $\mathrm{H}$-bonded Edge isomer of $1 \mathrm{NpOH} \cdot$ cyclopropane has a redshift of $\delta \tilde{v}=-72 \mathrm{~cm}^{-1} .35$ The spectral shifts of the $1 \mathrm{NpOH} \cdot n$-alkane complexes investigated here range from $\delta \tilde{v}=-3 \mathrm{~cm}^{-1}$ for $\mathrm{S}=$ propane and $n$-butane (isomer B) to $\delta \tilde{v}=-14.6 \mathrm{~cm}^{-1}$ for the $\mathrm{CH}_{4}$, which implies that they are Face complexes, see Table I.

\section{B. Long-lived metastable vibrational levels}

Out of about 30 complexes of carbazole and 1-naphthol that have been investigated by the SEP-R2PI method, ${ }^{13,35-38}$ only the methane and ethane complexes do not exhibit clear thresholds or breaking-off points in their hot-band SEP spectra, as seen in Figs. 7 and 8. We believe this is a consequence of essentially unhindered internal rotations of these two complexes, giving rise to a high density of internal-rotation states.

The SEP-R2PI method relies on IVR occurring from the dumped $S_{0}$ vibrational level of the complex into the intermolecular vibrations that lead to VP of the complex. 
These include the three translational-type vibrations, each of which leads to dissociation in the limit of large amplitude, as well as the hindered intermolecular rotational-type modes, i.e., rotational-type vibrations that couple strongly to the translational vibrations. Above the dissociation limit, all the available internal energy $E_{\text {exc }}$ must momentarily pool in one of dissociative coordinates for VP to occur. However, in the methane and ethane complexes, IVR also deposits energy in rotational-type vibrations that are weakly coupled to the translational-type modes, leading to slow dissociation. Such modes are the rotation of $\mathrm{CH}_{4}$ on the naphthalene surface, the rotation of the ethane parallel to the naphthalene surface, and internal rotation within the ethane moiety.

Since the first non-zero electrostatic moment of $\mathrm{CH}_{4}$ is the octupole moment, internal rotation couples weakly to dissociative (translational) motion and VP becomes much slower than for other complexes. If the time scale for VP therefore increases to the microsecond range, metastable population above the true $D_{0}$ is detected in the SEP-R2PI experiment, albeit with reduced intensity. With increasing excess energy above $D_{0}\left(S_{0}\right)$, VP can occur with the $\mathrm{CH}_{4}$ moiety in excited rotational states, leading to faster VP, so the SEP peaks become smaller.

The rotational constant of $\mathrm{CH}_{4}$ is $B_{0}=5.24 \mathrm{~cm}^{-1}$. If the rotation on the naphthalene surface were unhindered, the internal-rotation energy levels would be given by $E_{\text {int-rot }, 3 D}=B_{0} \cdot J(J+1)$. Given the $D_{0}=667 \pm 46 \mathrm{~cm}^{-1}$ dissociation energy of $1 \mathrm{NpOH} \cdot$ methane, internal-rotation levels of $1 \mathrm{NpOH} \cdot$ methane up $J=10-11$ lie below above the dissociation limit. The high rotational level degeneracy $g_{J}=(2 J+1)(2 J+1)$ of spherical-top molecules gives rise to a large density of internal-rotation states which can store a large fraction of the $S_{0}$ state internal energy without leading to VP.

As outlined above for $1 \mathrm{NpOH} \cdot$ methane, the intermolecular potential $D_{e}$ depends only weakly on $J$, and in the limit of free internal rotation, the potential energy curves of the $J=1$ and 2 internal-rotation states are expected to vertically offset by $2 B_{0}=10.48 \mathrm{~cm}^{-1}$ and $6 B_{0}=31.4 \mathrm{~cm}^{-1}$ relative to the $J=0$ potential energy surface. Interconversion between the lowest $J=0,1,2$ internal-rotation states cannot occur due to nuclear-spin restriction. Thus, the pump and dump steps are $J$-conserving. However, after the dump step, IVR involving $\Delta J=3,6, \ldots$ can occur. For example, 1-naphthol. $\mathrm{CH}_{4}$ complexes that start in $J=0$ and that are dumped into high $S_{0}$ vibrational levels close to $D_{0}$ can relax by IVR into internal-rotation levels with $J \geq=3$.

The rotational constant of ethane around its long axis is $A_{0}=2.52 \mathrm{~cm}^{-1}$. Long-axis rotation of the ethane moiety on the naphthalene is expected to be essentially free. We can approximate the vibrational level structure of this rotation-type intermolecular vibration as an unhindered $1 \mathrm{D}$ rotor, $E_{\text {int }- \text { rot }, 1 D}$ $=A_{0} \cdot l^{2}$, with internal-rotation quantum number $l=0, \pm 1$, $\pm 2, \ldots$ Given the $D_{0}=1207 \pm 30 \mathrm{~cm}^{-1}$ dissociation energy of $1 \mathrm{NpOH} \cdot$ ethane, one sees that internal-rotation levels can be populated up to about $l= \pm 21$. In addition, the intramolecular internal rotation within ethane can also take place; there are 12 internal-rotation levels below $D_{0}$ which also couple poorly to dissociation. This leads to a similar situation as for the methane complex; VP is slowed to a time scale that allows some of the dumped population to be detected above the dissociation threshold.

\section{Comparison of calculated and experimental dissociation energies}

Table II gives the $D_{0}$ values of the 1-naphthol- $n$-alkane complexes calculated using the three dispersion-corrected DFT methods discussed in Sec. II B; they are derived from the calculated intermolecular binding energies $D_{e}$ and the calculated changes of the harmonic vibrational zero-point energies ( $\triangle$ VZPEs) as $D_{0}=D_{e}-\triangle \mathrm{VZPE}$ and are compared to the experimental $D_{0}\left(S_{0}\right)$ values. We also compare the experimental $D_{0}$ values to the calculated ones in Fig. 11. For $\mathrm{S}=$ propane, we compare to the most stable Face 5 isomer, and for $n$-butane $\mathrm{A}$ and $\mathrm{B}$, we compare to the two most stable isomers denoted as trans Face $C$ and trans Face $C$; both of these involve the more stable trans-rotamer of $n$-butane.

Perhaps the most important aspect of Table II is that the intermolecular dispersion energy at the minimum-energy geometries of all the Face complexes, as estimated by the D3 correction, is calculated to be stabilizing and much larger than the $D_{0}$. In other words, none of the Face complexes would

TABLE II. Experimental and calculated $S_{0}$ state dissociation energies $D_{0}$, binding energies $D_{e}$, and vibrational zero-point energy differences $\Delta \mathrm{VZPE}$ (in kJ/mol) of the 1-naphthol $n$-alkane Face complexes. Calculations were done with the DFT methods B97-D3, B3LYP-D3, and $\omega$ B97X-D. The last column gives the D3 intermolecular dispersion energies at the B97-D3 optimized structures.

\begin{tabular}{|c|c|c|c|c|c|}
\hline Complex & Experimental & $\begin{array}{c}\mathrm{B} 97-\mathrm{D} 3 \\
D_{0}\left(D_{e}-\Delta \mathrm{VZPE}\right)\end{array}$ & $\begin{array}{c}\text { B3LYP-D3 } \\
D_{0}\left(D_{e}-\Delta \mathrm{VZPE}\right)\end{array}$ & $\begin{array}{c}\omega \mathrm{B} 97 \mathrm{X}-\mathrm{D} \\
D_{0}\left(D_{e}-\Delta \mathrm{VZPE}\right)\end{array}$ & D3 dispersion energy \\
\hline Methane & $7.98 \pm 0.55$ & $6.78(9.38-2.62)$ & $7.31(9.96-2.65)$ & $7.58(11.79-4.21)$ & 19.76 \\
\hline Ethane & $14.44 \pm 0.36$ & $12.11(15.20-3.09)$ & $12.65(15.74-3.09)$ & $14.16(17.93-3.78)$ & 29.53 \\
\hline Propane $^{\mathrm{a}}$ & $16.71 \pm 0.08$ & $16.27(19.68-3.41)$ & $17.46(20.74-3.28)$ & $19.83(23.33-3.50)$ & 38.71 \\
\hline$n$-butane A & $20.52 \pm 0.10$ & $20.15(23.90-3.76)^{\mathrm{b}}$ & $21.40(25.27-3.87)^{\mathrm{c}}$ & $24.84(28.56-3.72)^{b}$ & 46.33 \\
\hline$n$-butane B & $20.26 \pm 0.05$ & $20.07(24.10-4.03)^{c}$ & $21.33(24.96-3.63)^{\mathrm{b}}$ & $24.50(28.31-3.48)^{\mathrm{c}}$ & 46.85 \\
\hline $\mathrm{MAD}^{\mathrm{d}}$ & & 0.91 & 1.14 & 2.47 & \\
\hline
\end{tabular}

${ }^{\mathrm{a}}$ Calculated values for the most stable Face 5 isomer.

${ }^{\mathrm{b}}$ Calculated values for the trans Face $C$ isomer.

${ }^{\mathrm{c}}$ Calculated values for the trans Face $A$ isomer.

${ }^{\mathrm{d}}$ Mean absolute deviation between the five calculated and experimental values $(\mathrm{kJ} / \mathrm{mol})$. 


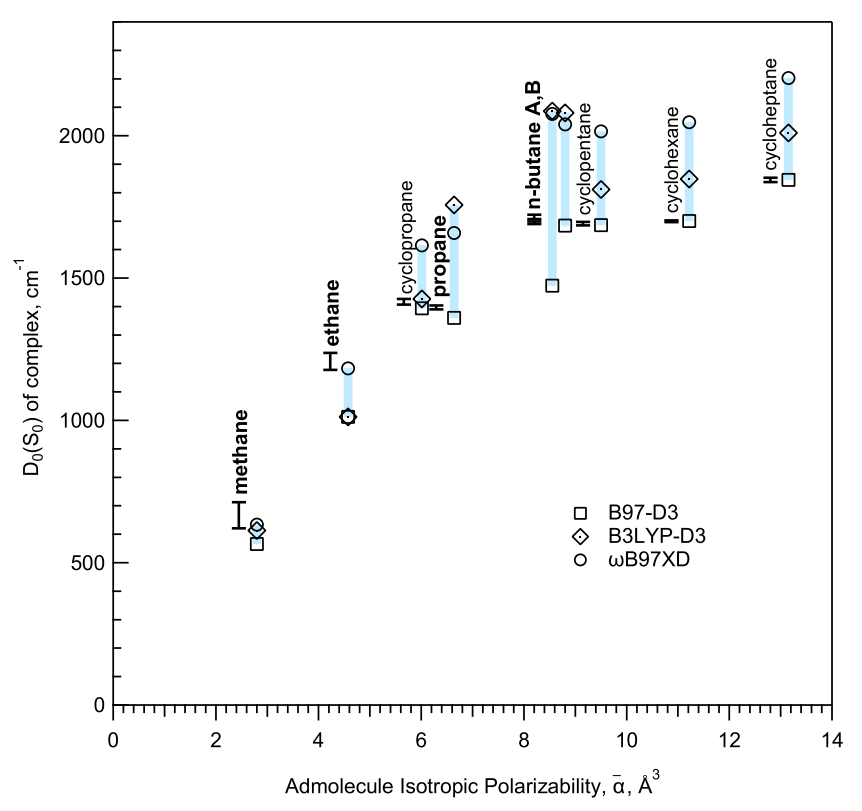

FIG. 11. Experimental and calculated SEP-R2PI ground-state dissociation energies $D_{0}\left(S_{0}\right)$ of the 1-naphthol· $n$-alkane complexes reported in this work (labeled in bold font) and in Ref. 35 with $\mathrm{S}=$ cycloalkane plotted vs. the average electronic polarizability $\bar{\alpha}$ of the adsorbate molecule. The calculated values are horizontally offset for clarity.

be bound without the $\mathrm{D} 3$ dispersion correction to the density functionals.

Considering the results in detail, and starting with the 1-naphthol. $\mathrm{CH}_{4}$ complex, one sees that the B97-D3 $D_{0}$ value is $15 \%$ smaller than the experimental $D_{0}$ and lies outside the experimental brackets. The B3LYP-D3 and $\omega$ B97X-D $D_{0}$ values are $8 \%$ and $5 \%$ smaller than the experimental $D_{0}$, both within the experimental brackets. For the ethane complex, the B97-D3 and B3LYP-D3 $D_{0}$ values are $16 \%$ and $12 \%$ smaller than the experimental $D_{0}$ and are 1.9 and $1.4 \mathrm{~kJ} / \mathrm{mol}$ outside the (much narrower) experimental brackets, respectively. Similar to the methane complex, the $\omega$ B97X-D $D_{0}$ is only $2 \%$ smaller than the experimental $D_{0}$ and lies within the experimental brackets. For the $1 \mathrm{NpOH}$.propane complex and the two isomers of the butane complex, the agreement between calculations and experiment is reversed: Now the B97-D3 and B3LYP-D3 values are in very good agreement, the B97-D3 predictions being about $3 \%$ below experiment and the B3LYPD3 $D_{0}$ values being $4 \%-5 \%$ larger than experiment. Here, the $\omega$ B97X-D $D_{0}$ values are $19 \%-21 \%$ larger than experiment. Overall, the B97-D3 $D_{0}$ values exhibit the smallest mean absolute deviation relative to experiment of mean absolute difference $(\mathrm{MAD})=0.91 \mathrm{~kJ} / \mathrm{mol}$, followed by the by the B3LYP-D3 method with $\mathrm{MAD}=1.14 \mathrm{~kJ} / \mathrm{mol}$ and the $\omega \mathrm{B} 97 \mathrm{X}-\mathrm{D}$ method with $\mathrm{MAD}=2.47 \mathrm{~kJ} / \mathrm{mol}$.

When comparing the B97-D3, B3LYP-D3, and $\omega$ B97X-D calculated $D_{0}$ values to those of experiment, the $D_{e}$ and $\Delta \mathrm{VZPE}$ values must be considered separately, since "good" $D_{0}$ values may fortuitously arise due to error compensation. Columns 3-5 of Table II show the binding energies $D_{e}$ and vibrational zero-point energy changes $\triangle \mathrm{VZPE}$ values in parentheses. In general, the B97-D3 and B3LYP-D3 binding energies are similar, the B3LYP-D3 values being about $5 \%$ or $0.5-1.4$ $\mathrm{kJ} / \mathrm{mol}$ larger. By contrast, the $\omega \mathrm{B} 97 \mathrm{X}-\mathrm{D} D_{e}$ values are about $20 \%$ (between 2.4 and $4.6 \mathrm{~kJ} / \mathrm{mol}$ ) larger than the B97-D3 values.

The $\triangle$ VZPE values calculated with the different methods are within $0.6 \mathrm{~kJ} / \mathrm{mol}$ of each other, with the exception of the $\omega \mathrm{B} 97 \mathrm{X}-\mathrm{D}$ value for the $\mathrm{CH}_{4}$ complex, which is $1.6 \mathrm{~kJ} / \mathrm{mol}$ larger than with B97-D3 and B3LYP-D3. Table II shows that $\triangle$ VZPE is $27 \%-35 \%$ of $D_{e}$ for the methane complex, decreasing to $20 \%-27 \%$ of $D_{e}$ for ethane and to $15 \%-17 \%$ of $D_{e}$ for the propane and $n$-butane A and B complexes. Thus, the $\triangle \mathrm{VZPE}$ corrections substantially influence the $D_{0}$ values.

This finding is similar to the 1-naphthol $\mathrm{N}_{2}$ complex, for which the $\triangle \mathrm{VZPE}$ is $21 \%$ of $D_{e} \cdot{ }^{37}$ By contrast, for the 1naphthol.S noble-gas complexes $(\mathrm{S}=\mathrm{Ne}-\mathrm{Xe})$, the $\triangle \mathrm{VZPE}$ contributions are between $7 \%$ and $12 \%$ of the $D_{e} \cdot{ }^{37}$ This difference arises mainly from the smaller number of intermolecular vibrations for the noble-gas complexes (three), while the admolecule complexes have five or six intermolecular vibrations.

Table III shows that the intermolecular VZPE contributes $60 \%-90 \%$ to the total $\triangle \mathrm{VZPE}$. The second contribution to $\triangle \mathrm{VZPE}$ arises from the changes of the intramolecular vibrational frequencies of the 1-naphthol and $n$-alkane moieties upon complex formation, $\Delta$ (intra), which exhibits a positive sign. This is a consequence of the slight compression of both complex partners by the dispersive intermolecular interaction which, on average, increases the intramolecular frequencies. These frequency changes are calculated to be quite small individually, typically between -6 and $+10 \mathrm{~cm}^{-1}$. For the $\mathrm{CH}_{4}$ complex, Table III shows that the sum of these

TABLE III. Experimental and B97-D3 calculated intermolecular fundamental frequencies and changes of the vibrational zero-point energies $\Delta$ VZPE (in $\mathrm{cm}^{-1}$ ) of the 1-naphthol· $n$-alkane Face complexes with $\mathrm{S}=$ methane, ethane, propane, and $n$-butane (isomers A and $\mathrm{B}$ ).

\begin{tabular}{|c|c|c|c|c|c|c|c|c|c|c|c|c|c|c|c|}
\hline \multirow[b]{2}{*}{ Admolecule } & \multicolumn{6}{|c|}{ Experimental freqs. } & \multicolumn{6}{|c|}{ B97-D3 harmonic freqs. } & \multicolumn{3}{|c|}{$\Delta$ VZPE (B97-D3 calc.) } \\
\hline & $\tilde{v}_{X}$ & $\tilde{v}_{Y}$ & $\tilde{v}_{Z}$ & $\tilde{v}_{r o t, 1}$ & $\tilde{v}_{r o t, 2}$ & $\tilde{v}_{r o t, 3}$ & $\tilde{v}_{X}$ & $\tilde{v}_{Y}$ & $\tilde{v}_{Z}$ & $\tilde{v}_{r o t, 1}$ & $\tilde{v}_{r o t, 2}$ & $\tilde{v}_{r o t, 3}$ & Inter (\%) & $\Delta$ intra $(\%)$ & Total \\
\hline Methane & 16.2 & 32.4 & 52.7 & 72.1 & $\cdots$ & $\cdots$ & 22.2 & 32.8 & 53.9 & 73.0 & 88.3 & 122.1 & 196(90) & $23(10)$ & 219 \\
\hline Ethane & 18.5 & $27.4 / 30.2$ & 40.8 & 74.2 & 84.0 & 103.0 & 35.4 & 39.4 & 48.6 & 70.9 & 87.5 & 109.5 & 196(77) & $59(23)$ & 255 \\
\hline Propane $^{\mathrm{a}}$ & 19.4 & 30.4 & 58.3 & 79.4 & $\cdots$ & 120.4 & 23.7 & 47.0 & 52.8 & 73.6 & 88.0 & 118.9 & 202(71) & $82(29)$ & 284 \\
\hline$n$-butane $\mathrm{A}^{\mathrm{b}}$ & 17.6 & 34.5 & 60.1 & $\ldots$ & 94 & $\cdots$ & 24.1 & 44.8 & 50.9 & 71.6 & 85.4 & 116.0 & 196(62) & 118(38) & 314 \\
\hline$n$-butane $\mathrm{B}^{\mathrm{c}}$ & 19.8 & 38 & 61.2 & $\ldots$ & $\ldots$ & $\ldots$ & 33.5 & 46.3 & 52.5 & 74.6 & 88.8 & 120.3 & $209(62)$ & $129(38)$ & 337 \\
\hline
\end{tabular}

${ }^{\mathrm{a}}$ Calculated values for the most stable Face 5 isomer.

${ }^{\mathrm{b}}$ Calculated values for the trans Face $C$ isomer.

${ }^{\mathrm{c} C}$ Calculated values for the trans Face $A$ isomer. 
contributions is $+23 \mathrm{~cm}^{-1}$, about $10 \%$ of the total $\triangle \mathrm{VZPE}$. However, these contributions increase rapidly with increasing size of the admolecule, being +118 and $+129 \mathrm{~cm}^{-1}$ for $n$-butane A and B complexes, corresponding to $38 \%$ of $D_{e}$.

The DFT-D calculated intermolecular vibrational frequencies, and to some extent also the $\triangle$ VZPE values, can be compared to experiment. The R2PI spectra of the $1 \mathrm{NpOH} \cdot n$-alkane complexes in Fig. 1 exhibit fundamental excitations of the translational-type intermolecular vibrations $\tilde{v}_{X}, \tilde{v}_{Y}$, and $\tilde{v}_{Z}$ and in some cases also distinct fundamentals of the rotational-type intermolecular vibrations $\tilde{v}_{r o t, 1}, \tilde{v}_{r o t, 2}$, and $\tilde{v}_{r o t, 3}$. (Since the excited-state dissociation energies are essentially unchanged from the ground-state $D_{0} \mathrm{~s}$, we expect that the $S_{1}$ state intermolecular vibrations differ little from their $S_{0}$ state counterparts, which were not measured.) Table III compares the B97-D3 calculated (harmonic) to the experimental $S_{1}$ state intermolecular frequencies, showing that many differ by only a few $\mathrm{cm}^{-1}$, the largest differences being $15 \mathrm{~cm}^{-1}$ $(0.1-0.2 \mathrm{~kJ} / \mathrm{mol})$. One also sees that the experimental wavenumbers tend to be lower than the calculated ones, the $\tilde{v}_{Z}$ wavenumbers of propane and butane being exceptions.

Judging from the B97-D3 calculated values in Table III, $60 \%-75 \%$ of the intermolecular VZPE of the $1 \mathrm{NpOH} \cdot n$-alkane complexes arises from the three rotational-type intermolecular vibrations. The R2PI spectra yields less information on these fundamentals, since the electronic excitation of the 1-naphthol moiety couples weakly to the rotational-type intermolecular coordinates, resulting in low Franck-Condon factors for these modes. Nevertheless, the R2PI spectra of $1 \mathrm{NpOH} \cdot$ ethane, $1 \mathrm{NpOH} \cdot$ propane, and $1 \mathrm{NpOH} \cdot n$-butane in Figs. 1(c)-1(e) exhibit several weak $\tilde{v}_{\text {rot }}$ fundamentals. Comparison to the B97-D3 calculated values reveals astonishingly good agreement. For the $1 \mathrm{NpOH} \cdot e$ thane complex, we observe all six intermolecular vibrations; if our vibrational assignments are correct, the sum of the vibrational frequencies is $351 \mathrm{~cm}^{-1}$. This compares favorably with the B97-D3 harmonically calculated $392 \mathrm{~cm}^{-1}$, indicating that the anharmonic experimental intermolecular frequencies are $\sim 10 \%$ lower than the harmonic calculated values.

In Fig. 12, we plot the B97-D3 def2-TZVPP calculated vibrational zero-point energies of the $1 \mathrm{NpOH}$ complexes with the $n$-alkanes and with the previously studied cycloalkanes ${ }^{36}$ vs. the mass of S. As might be expected, the change of the intramolecular ZPVE (red bars) increases with the number of intramolecular vibrations of $S$ and hence with the number of atoms in $\mathrm{S}$ and approximately with the mass of $\mathrm{S}$. The intermolecular ZPVE (blue bars) first shows a small increase with mass of $S$, decreasing for masses larger than propane. The sum of the inter- and intramolecular trends leads to a peak in the total $\triangle$ VZPE at propane. The large $\triangle$ VZPE of the cyclopentane complex is an exception; it reflects the increase of the pseudorotational intramolecular vibrational frequency from $3 \mathrm{~cm}^{-1}$ in bare cyclopentane to $100 \mathrm{~cm}^{-1}$ in the $1 \mathrm{NpOH}$ complex. Overall, the success of the dispersion-corrected DFT calculations depends both on the quality of the $D_{e}$ prediction and on the accuracy of the calculated inter- and intramolecular frequencies.

We specifically note the following: (1) For the $n$-alkane and cycloalkane complexes, the six intermolecular vibrations

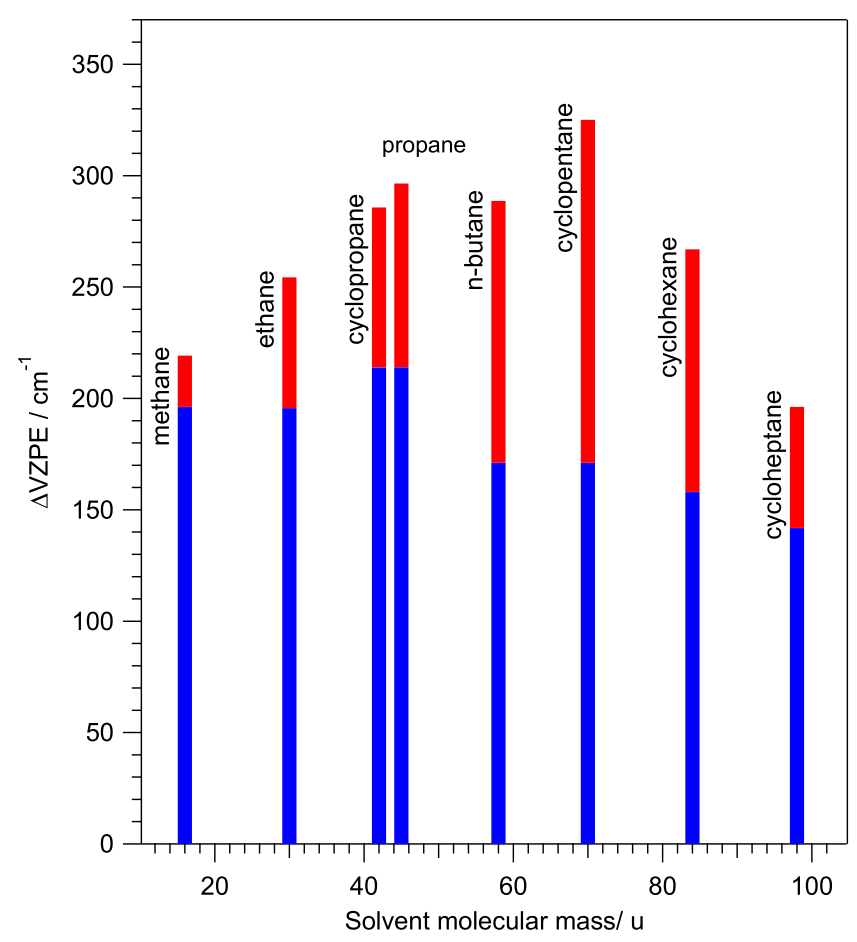

FIG. 12. Calculated changes of vibrational zero-point energies $\triangle$ VZPE of the 1-naphthol· $n$-alkanes and 1-naphthol-cycloalkanes (see Fig. 11) plotted vs. the mass of the (cyclo)alkane solvent. Blue bars: contributions to $\triangle$ VZPE from the intermolecular VZPE. Red bars: sum of the changes of the intramolecular ZPVEs of 1-naphthol and of the (cyclo)alkane.

contribute the largest share to $\triangle$ VZPE. (2) This contribution is largest for the lightest admolecule methane, where it predicted to be $26 \%-37 \%$ of the well depth $D_{e}$. (3) The VZPE contributions from the experimentally measured translational intermolecular vibrations agree well with the B97-D3 and B3LYP-D3 calculated ones. (4) The VZPE contributions from the rotational-type vibrations could only be experimentally studied for $\mathrm{S}=$ methane, ethane, and propane; the differences with respect to the calculations are variable and need to be carefully monitored in the future. (5) Similar to the $1 \mathrm{NpOH} \cdot \mathrm{N}_{2}$ complex ${ }^{37}$ substantial errors of the harmonic VZPE treatment might arise for the internal-rotation-type intermolecular modes of the methane complexes. We expect improvements of the calculated $\triangle \mathrm{VZPE}$ contributions from more accurate anharmonic treatments of the rotational-type intermolecular vibrations.

The latter findings are similar to those previously noted for small hydrogen-bonded dimers, such as $\left(\mathrm{H}_{2} \mathrm{O}\right)_{2},\left(\mathrm{NH}_{3}\right)_{2}$, $(\mathrm{HF})_{2}$, or $(\mathrm{HCl})_{2}$, where the $\triangle \mathrm{VZPE}$ amounts to $25 \%-40 \%$ of the $D_{e}$ and where the theoretical determination of $D_{0}$ crucially depends on the anharmonic treatment of VZPE and of $\triangle$ VZPE. ${ }^{54}$

\section{Comparison to dissociation energies of benzene. $n$-alkanes}

Fujii et al. have investigated the dissociation energies of $\mathrm{Bz} \cdot \mathrm{S}$ complexes with $\mathrm{S}=$ methane, ethane, propane, $n$-butane, iso-butane, and cyclohexane. ${ }^{39,40}$ Comparing their set of $D_{0}\left(S_{0}\right)$ with the current set allows us to investigate the 
influence of the chromophore molecule (which we denote as M) on the dissociation energy.

Fujii et al. derived the $D_{0}$ of the neutral complex via an energy cycle involving the ionization potential (IP) energy of $\mathrm{Bz}$, the IP of Bz.S, and the appearance potential (AP) of the $\mathrm{Bz}^{+}$fragment ion that is formed when ionizing the $\mathrm{Bz} \cdot \mathrm{S}$ complex sufficiently high above its IP to leads to fragmentation. This gives $D_{0}\left(S_{0} ;\right.$ neutral $)=D_{0}\left(\mathrm{Bz}^{+} \cdot \mathrm{S}\right)+\mathrm{IP}(\mathrm{Bz} \cdot \mathrm{S})-\mathrm{IP}(\mathrm{Bz})$. The APs for benzene-methane and benzene- $d_{6}$. methane were measured with the two-color mass-analyzed threshold ionization (MATI) technique. ${ }^{39}$ For the Bz.S complexes with $\mathrm{S}=$ ethane and larger, the APs were measured as the ion current onsets in the benzene ${ }^{+}$fragment ion channel. The experimental values were compared to $\operatorname{CCSD}(\mathrm{T})$ calculations of the neutral benzene-S dissociation energies, which agree well with the measured values. ${ }^{39,40}$

These three measurements, IP of Bz, IP of the Bz.S complex, and the corresponding AP, involve errors that increase in that order, although the size of the errors of the two IP measurements were not mentioned in Refs. 39 and 40. We also note that this method assumes that the adiabatic IPs of the Bz.S complexes are measurable. However, if the geometry of the Bz.S and $\mathrm{Bz}^{+} \cdot \mathrm{S}$ complexes are sufficiently different, the FranckCondon factors for neutral $\rightarrow$ ion transitions at the adiabatic IP will be very small, the onset of the ion current will be very gradual, and the adiabatic IP may not be measurable. Since the additional ion $\rightarrow$ induced-dipole interaction between the $\mathrm{Bz}^{+}$ ion and the $\mathrm{S}$ moiety both increases the $D_{0}$ and changes the geometry of the complex ion relative to the neutral complex, it is possible that the adiabatic IP may become inaccessible by photoionization.

Despite these caveats, it is instructive to compare the $D_{0}\left(S_{0}\right)$ values of these benzene. $S$ complexes with those of similar 1-naphthol complexes. In Fig. 13(a), we plot the experimental values against the average electronic polarizability $\bar{\alpha}$ of the admolecules. The dissociation energies of the benzene complexes exhibit a similar pattern as discussed in Sec. III C for the $1 \mathrm{NpOH}$ complexes, with an initial roughly linear increase with the polarizability up to $\mathrm{S}=$ ethane, followed by a slower rise and a nearly flat plateau up to cyclohexane. The similarity of the two patterns becomes even clearer in Fig. 13(b), in which we normalized the $D_{0}$ values by the average polarizability of the chromophore molecule $\mathrm{M}$. The normalized $D_{0}$ values of the two sets of complexes are seen to coincide within the (larger) error bars of the benzene complexes. This plot implies that the intermolecular binding energies of these two sets of complexes are approximately proportional to the polarizability $\alpha_{M}$. This is interesting since a similar proportionality is not found for the solvent molecules. However, an important characteristic of both benzene and 1-naphthol is that they are planar. This means that the three-dimensional effects which were found to be essential for understanding the solvent series are not operative for the substrate molecules. A different, nonplanar, choice of $\mathrm{M}$ would presumably not result in such a close correlation as in Fig. 13(b).

We also investigated how well the Eisenshitz-London equation ${ }^{1,2}$ applies to these two data sets. As noted above, this was derived for interacting atoms, not molecules. It expresses

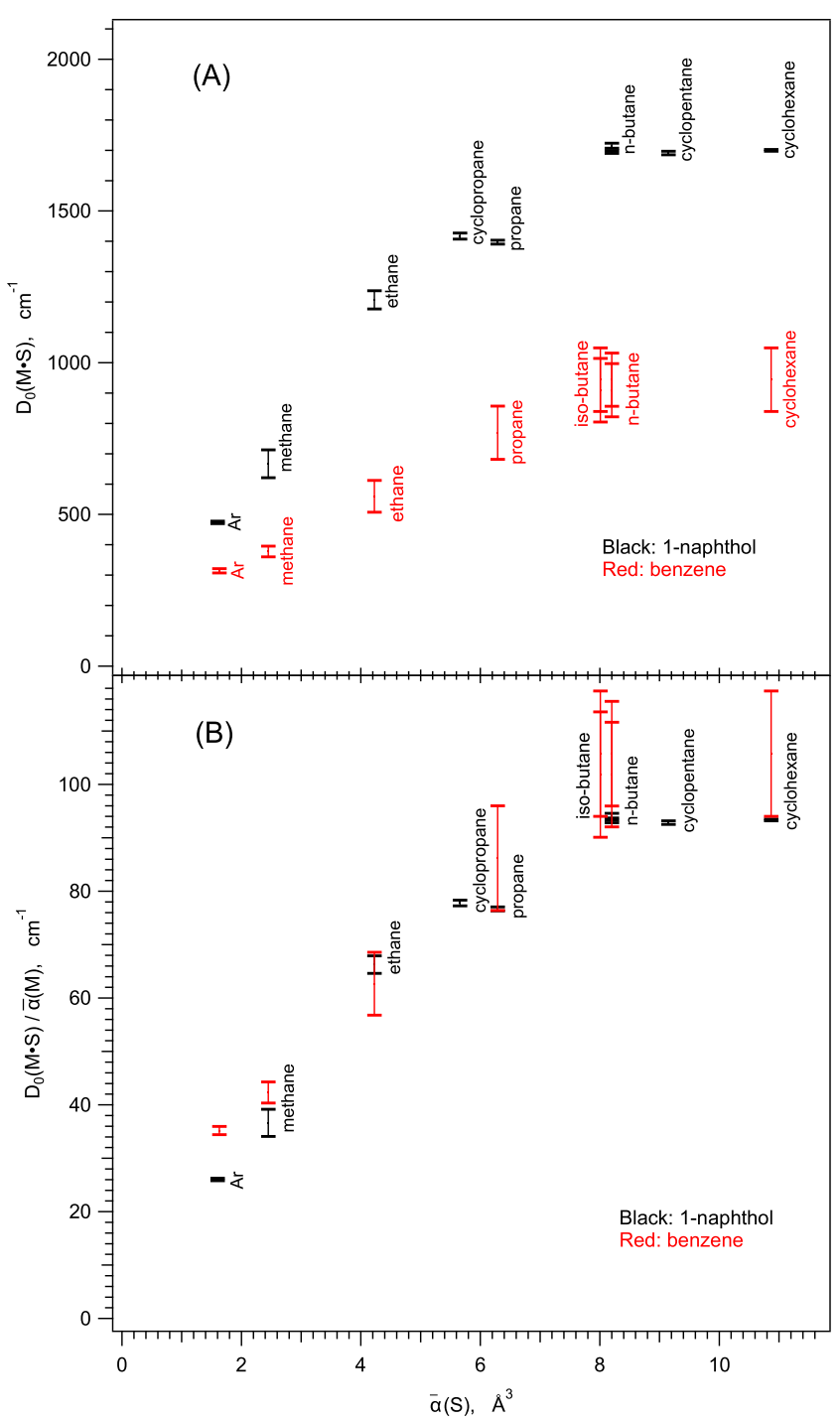

FIG. 13. (a) Comparison of the experimental $S_{0}$ state dissociation energies $D_{0}$ of the 1-naphthol.S complexes (in black) and the analogous benzene. $\mathrm{S}$ complexes (in red, values from Refs. 39 and 40) plotted vs. the average electronic polarizability $\bar{\alpha}$ of the solvent S. (b) The same x-axis as in (a), but with the $D_{0}$ values normalized by the average polarizability of the chromophore, $\bar{\alpha}(M)$.

the dispersive binding energy as the product of the polarizabilities, $\alpha_{A} \cdot \alpha_{B}$, multiplied with the geometric mean of the IPs of the two atoms, $\left(\mathrm{IP}_{A} \cdot \mathrm{IP}_{B}\right) /\left(\mathrm{IP}_{A}+\mathrm{IP}_{B}\right)$. However, while the lower part of this plot (Fig. S2 of the supplementary material) is approximately linear up to benzene-propane, thereafter the two sets of $D_{0}$ values diverge much more than in Fig. 13(b). The IP factor is evidently the less accurate part of the equation, not the polarizability product. The IP factor arises as an atomic approximation to the frequency dependence of the polarizability and assumes there is only one absorption band in the atomic spectrum. Clearly these approximations are not appropriate for molecular complexes, especially the aromatic substrates benzene and 1-naphthol.

\section{CONCLUSIONS}

We determined accurate intermolecular dissociation energies $D_{0}$ for the 1-naphthol.S complexes with $\mathrm{S}=$ methane, 
ethane, propane, and $n$-butane (two isomers) using the stimulated-emission pumping resonant two-photon ionization (SEP-R2PI) method. The ground-state dissociation energies $D_{0}\left(S_{0}\right)$ were bracketed within $\pm 0.55 \mathrm{~kJ} / \mathrm{mol}$ for $\mathrm{S}=$ methane, \pm $0.36 \mathrm{~kJ} / \mathrm{mol}$ for the ethane complex, and within $\pm 0.1 \mathrm{~kJ} / \mathrm{mol}$ for propane and $n$-butane (both isomers). The dissociation energies $D_{0}$ in the $S_{1}$ excited state change very little relative to the $S_{0}$ state: by $2 \%$ for the methane complex and by $<0.35 \%$ for the ethane, propane, and $n$-butane complexes.

The small spectral shifts of the 1-naphthol- $n$-alkane indicate that these form dispersively bound Face structures, similar to the complexes of 1-naphthol with the cycloalkanes and the noble gases. ${ }^{35-37}$ The only spectroscopic indications of possible Edge isomers are broad and weak spectral tails on the low-wavenumber side of the intense $0_{0}^{0}$ bands. UV/UVholeburning spectroscopy allowed separation of these tails from the narrow and intense bands of the Face isomers. We propose that the tails arise from incompletely cooled Edge isomers.

The $D_{0}\left(S_{0}\right)$ values of the $n$-alkane complexes increase monotonically with increasing average electronic polarizability $\bar{\alpha}$ of the $n$-alkane, in qualitative, but not quantitative, agreement with the Eisenshitz-London model for dispersive interactions. ${ }^{1,2}$ Combining the SEP-R2PI dissociation energies of the $n$-alkane complexes with those of the previously measured dispersively bound noble-gas complexes with $\mathrm{S}=\mathrm{Ar}, \mathrm{Kr}$, and $\mathrm{Xe}^{37}$ and cycloalkane Face isomers ${ }^{35,36}$ gives a set of 1-naphthol-S complexes with dissociation energies ranging from $D_{0}=480$ to $1800 \mathrm{~cm}^{-1}$. Plotting the $D_{0}$ values against the average electronic polarizability $\bar{\alpha}$ that ranges from 1.6 to $13 \AA^{3}$ reveals a reasonably linear correlation with $\bar{\alpha}$ up to about $5 \AA^{3}$. For solvent molecules with larger $\bar{\alpha}$, the correlation becomes sublinear and seems to saturate with increasing $\bar{\alpha}$. This saturation can be attributed to the differentially smaller increase of the dispersive interaction as the adsorbate molecule covers or extends beyond the periphery of the 1-naphthol molecule. We also note that the Eisenshitz-London model was designed to model the dispersive interactions between two atoms and the correlation with the average electronic polarizability $\bar{\alpha}$ is not well-defined for large anisotropic molecules such as the $n$-alkanes and cycloalkanes.

We have calculated the structures, binding energies $D_{e}$, vibrational frequencies, and changes of vibrational zero-point energy $(\triangle \mathrm{VZPE})$ of the 1 -naphthol $\cdot n$-alkane complexes using the three dispersion-corrected density functional methods B97-D3, B3LYP-D3, and $\omega$ B97X-D. For the methane and ethane complexes, a single Face isomer was found and no Edge isomer could be optimized. For the propane complex, all DFT-D methods predicted five Face isomers; all of these are much more stable than the single Edge isomer. For this reason, no Edge isomers of the $n$-butane were investigated. The trans-butane complexes are calculated to exist in (at least) 13 isomers. Our comparisons of theory and experiment refer to the $D_{0}$ values of the most stable isomers.

We compared the $D_{0}$ values calculated by the three DFT methods for the 1-naphthol. $n$-alkane complexes: The B97-D3 method reproduced the experimental $D_{0}$ values for $\mathrm{S}=$ propane and the two $n$-butane complexes with a mean absolute difference (MAD) of $0.33 \mathrm{~kJ} / \mathrm{mol}$ and a maximum difference of $0.44 \mathrm{~kJ} / \mathrm{mol}$ (for propane). This good predictive performance was previously noted for the cycloalkane complexes. ${ }^{36}$ However, for $\mathrm{S}=$ methane and ethane, the best agreement of calculated and experimental $D_{0}$ is observed for the $\omega$ B97X-D method, both of which lie within the experimental $D_{0}$ brackets, while the B97-D3 and B3LYP-D3 dissociation energies are 15-16 and 8\%-12\% smaller than the experimental values. Note that if the DFT-D calculations do not predict the correct ordering of the propane and $n$-butane complexes, then the experimentally most stable isomer/s formed in the supersonic jet is/are not the same as calculated, implying that the agreement is less good.

As shown in the last column of Table II, the D3 dispersion energy at the minimum-energy Face geometries is calculated to be stabilizing and typically much larger than the $D_{0}$. In fact, none of the $n$-alkane Face isomers would be bound without the D3 corrections to the density functionals.

The VZPE contribution to $D_{0}$ and the $\triangle$ VZPE correction were examined experimentally and theoretically. In contrast to the noble-gas complexes, for which the calculated intermolecular VZPEs are only $4 \%-11 \%$ of the binding energy $D_{e}$, the contribution from intermolecular VZPE is much larger if $\mathrm{S}$ is a molecule, because of the three additional rotation-type intermolecular vibrations. For the $n$-alkane complexes, the calculated intermolecular VZPEs are 18\%-37\% of the calculated intermolecular well depth $D_{e}$. All three translation-type and several rotational-type $S_{1}$ state intermolecular vibrations were experimentally observed. For the propane complex, all six intermolecular $S_{1}$ state vibrations were identified, allowing detailed comparison to calculation. The anharmonic experimental frequencies are $\sim 7 \%$ smaller than the harmonic calculated B97-D3 frequencies. In this case, the harmonic B97-D3 calculation overestimates the intermolecular VZPE by about $15 \mathrm{~cm}^{-1}$ or $0.16 \mathrm{~kJ} / \mathrm{mol}$.

Together with the $D_{0}$ values of other previously measured intermolecular complexes, ${ }^{13,55}$ the $D_{0}$ values of these 1-naphthol-n-alkane complexes can serve as benchmarks for testing both highly correlated $a b$ initio calculations and density functional methods, as well as for improving the understanding and modeling of intermolecular interactions.

\section{SUPPLEMENTARY MATERIAL}

See supplementary material for tables of Cartesian coordinates of the 1-naphthol- $n$-alkane complexes optimized by the DFT methods (Tables S1-S14).

\section{ACKNOWLEDGMENTS}

We thank the Swiss National Science Foundation for financial support (Grant No. 200021E-160404) as well as the Priority Program SPP1807 "Control of London dispersion interactions in molecular chemistry" of the DFG.

\footnotetext{
${ }^{1}$ F. London, Z. Phys. 63, 245 (1930).

${ }^{2}$ R. Eisenschitz and F. London, Z. Phys. 60, 491 (1930).

${ }^{3}$ G. C. Maitland, M. Rigby, E. B. Smith, and W. A. Wakeham, Intermolecular Forces: Their Origin and Determination (Clarendon Press, Oxford, 1981).

${ }^{4}$ A. J. Stone, The Theory of Intermolecular Forces, 2 nd ed. (Oxford University Press, Oxford, UK, 2013).

${ }^{5}$ P. E. S. Wormer and A. van der Avoird, Chem. Rev. 100, 4109 (2000).
} 
${ }^{6}$ G. R. Desiraju and T. Steiner, The Weak Hydrogen Bond in Structural Chemistry and Biology (Oxford University Press, 2001).

${ }^{7}$ T. Steiner, Angew. Chem., Int. Ed. 41, 48 (2002).

${ }^{8}$ M. Mons, I. Dimicoli, and F. Piuzzi, Int. Rev. Phys. Chem. 21, 101 (2002).

${ }^{9}$ L. Goerigk and S. Grimme, Phys. Chem. Chem. Phys. 13, 6670 (2011).

${ }^{10}$ P. Hobza, Acc. Chem. Res. 45, 663 (2012).

${ }^{11}$ C. D. Sherrill, Acc. Chem. Res. 46, 1020 (2013).

${ }^{12}$ J. P. Wagner and P. Schreiner, Angew. Chem., Int. Ed. 54, 12274 (2015).

${ }^{13}$ J. A. Frey, C. Holzer, W. Klopper, and S. Leutwyler, Chem. Rev. 116, 5614 (2016).

${ }^{14}$ P. Jurečka, J. Šponer, J. Černy, and P. Hobza, Phys. Chem. Chem. Phys. 8, 1985 (2006).

${ }^{15}$ K. E. Riley, M. Pitoňák, P. Jurečka, and P. Hobza, Chem. Rev. 110, 5023 (2010).

${ }^{16}$ T. Takatani, E. G. Hohenstein, M. Malagoli, M. S. Marshall, and C. D. Sherrill, J. Chem. Phys. 132, 144104 (2010).

${ }^{17}$ R. Podeszwa, K. Patkowski, and K. Szalewicz, Phys. Chem. Chem. Phys. 12, 5974 (2010).

${ }^{18}$ C. Holzer and W. Klopper, Mol. Phys. 115, 2775 (2017).

${ }^{19}$ C. Holzer and W. Klopper, J. Chem. Phys. 147, 181101 (2017).

${ }^{20}$ R. A. Mata and M. A. Suhm, Angew. Chem., Int. Ed. 56, 11011 (2017).

${ }^{21}$ S. Grimme, J. Comput. Chem. 25, 1463 (2004).

${ }^{22}$ S. Grimme, J. Comput. Chem. 27, 1787 (2006).

${ }^{23}$ J.-D. Chai and M. Head-Gordon, Phys. Chem. Chem. Phys. 10, 6615 (2008).

${ }^{24}$ S. Grimme, Wiley Interdiscip. Rev.: Comput. Mol. Sci. 1, 211 (2011).

${ }^{25}$ S. Grimme, A. Hansen, J. G. Brandenburg, and C. Bannwarth, Chem. Rev. 116, 5105 (2016).

${ }^{26}$ L. Goerigk and S. Grimme, J. Chem. Phys. 132, 184103 (2010).

${ }^{27}$ S. Grimme, J. Antony, S. Ehrlich, and H. Krieg, J. Chem. Phys. 132, 154104 (2010).

${ }^{28}$ W. Hujo and S. Grimme, Phys. Chem. Chem. Phys. 13, 13942 (2011).

${ }^{29}$ J. F. Ogilvie and F. Y. H. Wang, J. Mol. Struct. 273, 277 (1992).

${ }^{30}$ J. F. Ogilvie and F. Y. H. Wang, J. Mol. Struct. 291, 313 (1993).

${ }^{31}$ T. Droz, T. Bürgi, and S. Leutwyler, J. Chem. Phys. 103, 4035 (1995).

${ }^{32}$ T. Bürgi, T. Droz, and S. Leutwyler, J. Chem. Phys. 103, 7228 (1995).

${ }^{33}$ T. Bürgi, T. Droz, and S. Leutwyler, Chem. Phys. Lett. 246, 291 (1995).

${ }^{34}$ C. Wickleder, T. Droz, T. Bürgi, and S. Leutwyler, Chem. Phys. Lett. 264, 257 (1997).
${ }^{35}$ S. Maity, R. Knochenmuss, C. Holzer, G. Féraud, J. A. Frey, W. Klopper, and S. Leutwyler, J. Chem. Phys. 145, 164304 (2016).

${ }^{36}$ S. Maity, P. Ottiger, F. A. Balmer, R. Knochenmuss, and S. Leutwyler, J. Chem. Phys. 145, 244314 (2016).

${ }^{37}$ R. Knochenmuss, R. K. Sinha, and S. Leutwyler, J. Chem. Phys. 148, 134302 (2018).

${ }^{38}$ R. Knochenmuss, S. Maity, and S. Leutwyler, Chimia 71, 7 (2017).

${ }^{39}$ K. Shibasaki, A. Fujii, N. Mikami, and S. Tsuzuki, J. Phys. Chem. A 110, 4397 (2006).

${ }^{40}$ A. Fujii, H. Hayashi, J. W. Park, T. Kazama, N. Mikami, and S. Tsuzuki, Phys. Chem. Chem. Phys. 13, 14131 (2011).

${ }^{41}$ H.-L. Dai and R. W. Field, Molecular Dynamics and Spectroscopy by Stimulated Emission Pumping (World Scientific, Singapore, 1995).

${ }^{42}$ C. Wickleder, D. Henseler, and S. Leutwyler, J. Chem. Phys. 116, 1850 (2002).

${ }^{43}$ M. J. Frisch, G. W. Trucks, H. B. Schlegel, G. E. Scuseria, M. A. Robb, J. R. Cheeseman, G. Scalmani, V. Barone, B. Mennucci, G. A. Petersson et al., Gaussian 09, Revision A.02, Gaussian, Inc., Wallingford, CT, 2009.

${ }^{44}$ F. A. Balmer, P. Ottiger, C. Pfaffen, and S. Leutwyler, J. Phys. Chem. A 117, 10702 (2013).

${ }^{45}$ F. A. Balmer, P. Ottiger, and S. Leutwyler, J. Phys. Chem. A 119, 10462 (2015).

${ }^{46}$ A. Amirav and J. Jortner, Chem. Phys. 85, 19 (1984).

${ }^{47}$ J. Bösiger and S. Leutwyler, Chem. Rev. 90, 489 (1990).

${ }^{48}$ N. Ben-Horin, U. Even, J. Jortner, and S. Leutwyler, J. Chem. Phys. 97, 5296 (1992).

${ }^{49}$ CRC Handbook of Chemistry and Physics, 84th ed., edited by D. R. Lide (CRC Press, Boca Raton, FLA, 2004).

${ }^{50}$ B. B. Champagne, J. F. Pfanstiel, D. W. Pratt, and R. C. Ulsh, J. Chem. Phys. 102, 6432 (1995).

${ }^{51}$ S. A. Wittmeyer, T. Troxler, and M. Topp, J. Phys. Chem. 97, 10613 (1993).

${ }^{52}$ K. Yamanouchi, S. Isogai, and S. Tsuchiya, J. Mol. Struct. 146, 349 (1986).

${ }^{53}$ M. Zierhut, W. Roth, S. Dümmler, and I. Fischer, Chem. Phys. 305, 123 (2004).

${ }^{54}$ A. K. Samanta, Y. Wang, J. S. Mancini, J. M. Bowman, and H. Reisler, Chem. Rev. 116, 4913 (2016).

${ }^{55}$ S. Haldar, R. Gnanasekaran, and P. Hobza, Phys. Chem. Chem. Phys. 17, 26645 (2015). 